\title{
The Application of Moment Methods to the Analysis of Fluid Electrical Conductivity Logs in Boreholes
}

\author{
Simon Loew \\ COLENCO Power Consulting Ltd. \\ Baden, Switzerland \\ Chin-Fu Tsang and Frank V. Hale \\ Earth Sciences Division \\ Lawrence Berkeley Laboratory \\ University of California \\ Berkeley, California 94720 \\ Peter Hufschmied \\ NAGRA, now at EMCH and Berger Ltd. \\ Bern, Switzerland
}

August 1990

This work was supported by the Manager, Chicago Operations, Repository Technology Program, Repository Technology and Transportation Division, of the U.S. Department of Energy under Contract No. DEAC03-76SF00098 and by the Swiss National Cooperative for the Storage of Nuclear Waste (NAGRA). 


\section{Preface}

This report is one of a series documenting the results of the Nagra-DOE Cooperative (NDC-I) research program in which the cooperating scientists explore the geological, geophysical, hydrological, geochemical, and structural effects anticipated from the use of a rock mass as a geologic repository for nuclear waste. This program was sponsored by the U. S. Department of Energy (DOE) through the Lawrence Berkeley Laboratory (LBL) and the Swiss Nationale Genossenschaft fur die Lagerung radioaktiver Abfalla (Nagra) and concluded in September 1989. The principal investigators are Jane C. S. Long, Ernest L. Majer, Karsten Pruess, Kenzi Karasaki, Chalon Carnahan and Chin-Fu Tsang for LBL and Piet Zuidema, Peter Blumling, Peter Hufschmied and Stratis Vomvoris for Nagra. Other participants will appear as authors of the individual reports. Technical reports in this series are listed below.

1. Determination of Fracture Inflow Parameters with a Borehole Fluid Conductivity Logging Method by Chin-Fu Tsang, Peter Hufschmied, and Frank V. Hale (NDC-1, LBL-24752).

2. A Code to Compute Borehole Fluid Conductivity Profiles with Multiple Feed Points by Frank V. Hale and Chin-Fu Tsang (NDC-2, LBL-24928; also NTB 88-21).

3. Numerical Simulation of Alteration of Sodium Bentonite by Diffusion of lonic Groundwater Components by Janet S. Jacobsen and Chalon L. Carnahan (NDC-3, LBL-24494).

4. P.Wave Imaging of the FRI and BK Zones at the Grimsel Rock Laboratory by Ernest L. Majer, John E. Peterson Jr., Peter Blumling, and Gerd Sattel (NDC-4, LBL-28807).

5. Numerical Modeling of Gas Migration at a Proposed Repository for Low and Intermediate Level Nuclear Wastes at Oberbauenstock, Switzerland by Karsten Pruess (NDC-5, LBL-25413).

6. Analysis of Well Test Data from Selected Intervals in Leuggern Deep Borehole - Verification and Application of PTST Method by Kenzi Karasaki (NDC-6, LBL-27914).

7. Shear Wave Experiments at the U. S. Site at the Grimsel Laboratory by Ernest L. Majer, John E. Peterson Jr., Pettr Blltmling, and Gerd Sattel (NDC-7 LBL-28808).

8. The Application of Moment Methods to the Analysis of Fluid Electrical Conductivity Logs in Boreholes by Simon Loew, Chin-Fu Tsang, Frank V. Hale, and Peter Hufschmied (NDC-8, LBL28809).

9. Numerical Simulation of Cesium and Strontium Migration through Sodium Bentonite Altered by Cation Exchange with Groundwater Components by Janet S. Jacobsen and Chalon L. Carnahan (NDC-9, LBL-26395).

10. Theory and Calculation of Water Distribution in Bentonite in a Thermal Field by Chalon L. Carnahan (NDC-10, LBL-26058).

11. Prematurely Terminated Slug Tests by Kenzi Karasaki (NDC-11, LBL-27528),

12. Hydrologic Characterization of Fractured Rocks - An Interdisciplinary Methodology by Jane C. S. Long, Emest L. Majer, Stephen J. Martel, Kenzi Karasaki, John E. Peterson Jr., Amy Davey, and Kevin Hestir, (NDC-12, LBL-27863).

13. Explorawry Simulations of Multiphase Effects in Gas Injection and Ventilation Tests in an Underground Rock Laboratory by Stefan Finsterle, Erika Schlueter, and Karsten Pruess (NDC-13, LBL. 28810).

14. Joint Seisn,ic, Hydrogeological, and Geomechanical Investigations of a Fracture Zone in the Grimsel Rock Laboratory, Switzerland by Ernest L. Majer, Larry R. Myer, John E. Peterson Jr., Kenzi Karasaki, Jane C. S. Long, Stephen J. Marel, Peter Bllumling, and Stratis Vnmvoris (NDC-14, LBL27913).

15. Analysis of Hydraulic Data from the MI Fracture Zone at the Grimsel Rock Laboratory, Swiverland by Amy Davey, Kenzi Karasaki, Jane C.S. Long, Martin Landsfeld, Antoine Mensch, and Stephen J. Martel (ND - -15, LBL.-27864).

16. Use of Integrated Geologic and Geophysical Information for Characterizing the Structure of Fracture Systems at the US/BK Site, Grimsel Laboratory, Swizerland by Stephen J. Martel and John E. Peterson Jr. (NDC-16, LBL-27912). 


\section{ABSTRACT}

Previous reports have presented a procedure for analyzing a time sequence of wellbore electric conductivity logs in order to obtain outflow parameters of fractures intercepted by the borehole (TSANG et a1. 1990), and a code, called BORE, used to simulate borehole fluid conductivity profiles given these parameters (Hale and Tsang, 1988). The present report describes three new direct (not iterative) methods for analyzing a short time series of electric conductivity logs based on moment quantities of the individual outflow peaks and applies them to synthetic as well as to field data. The results of the methods discussed show promising results and are discussed in terms of their respective advantages and limitations. In particular it is shown that one of these methods, the so-called "Partial Moment Method", is capable of reproducing packer test results from field experiments in the Leuggern deep well within a factor of three, which is below the range of what is recognized as the precision of packer tests themselves. Furthermore the new method is much quicker than the previously used iterative fitting procedure and is even capable of handling transient fracture outflow conditions. 


\section{ZUSAMMENFASSUNG}

Der vorliegende Bericht beschreibt drei neue Methoden für die quantitative Analyse von dynamischen (unter Absenkungsbedingungen durchgeführten) Fluid-Leitfähigkeitsmessungen in Bohrungen. Die neuen Analysenmethoden stellen wirkungsvolle Ergänzungen und Weiterentwicklungen einer in TSANG et al. (1990) präsentierten Feld-und Auswertungsmethodik dar, welche auf einem "best-fit" Simulationsverfahren der gemessenen Leitfähigkeitslogs beruht. Beide Verfahren ermöglichen eine exakte Lokalisierung von wasserleitenden Klüften oder diskreten, wasserführenden Zonen $(+/-1 \mathrm{~m}$ in $1000 \mathrm{~m}$ tiefen Bohrlöchern) und die Bestimmung der Transmissivität (und der Ruhewasser-Potentiale) der einzelnen Klüfte.

Die drei neuen Analysenverfahren, welche in vorliegendem Bericht entwickelt und dargestellt werden, basierten auf der "klassischen" Momentenmethode, welche zur Charakterisierung von Transportparametern eines Tracerpulses eingesetzt werden (z.B. FISCHER et a7. 1979). In vorliegendem Bericht werden analoge Beziehungen für die spezifischen Randbedingungen der Fluid-Logging Methode hergeleitet und an synthetischen und natürlichen Datensätzen ausgetestet.

Nach einer allgemeinen Diskussion des Testverfahrens und der AnalysenGrundgleichung (Kapitel 1) werden die Beziehungen des nullten und ersten Momentes eines Einzelkluftzuflusses zum Bohrloch zu den Kluftparametern "Fliessrate" und "Elektrolyt-Konzentration" hergeleitet (Kapitel 2). Einzelkluftzuflüsse werden dadurch charakterisiert, dass ihre Peaks auf Leitfähigkeitslogs nicht miteinander interferieren und darum relativ einfach individuell analysiert werden können.

Kapitel 3 und 4 präsentieren neue Analysenverfahren für den allgemeinen Fall von interferierenden Zuflusspeaks, welche mit "klassischen" Momentenansätzen nicht ausgewertet werden können. Die Methode der Partiellen Momente (Kapitel 3) basiert auf Zeitableitungen von Integralwerten mit ähnlicher Struktur wie jene der klassischen Momente, definiert jedoch für Log-Abschnitte zwischen aufeinanderfolgenden Zuflussstellen. Die Annahmen dieser Methode liegen einzig darin, dass innerhalb solcher Integrationsgrenzen sowohl die lineare Bohrlochgeschwindigkeit wie der Dispersionskoeffizient konstant sind. Aus diesem Grund erlaubt die Methode theoretisch für jeden Boirlochabschnitt und jedes Zeitintervall unabhängig (d.h. transient) den volumetrischen Fluss (und daher auch aus den entsprechenden Flussdifferenzen die Kluftzuflüsse) zu bestimmen. Die Nachteile und Einschränkungen der Methode liegen in ihrer potentiellen numerischen Instabilität zu späten Zeiten.

Die Direkte Integral Methode (Kapitel 4) basiert auf MassenbilanzApproximationen und klassischen nullten Momenten zu frühen LoggingZeiten. Der Elektrolyttransport wird gegenüber der weiter oben verwendeten 10-advektiven-diffusiven Transportgleichung in dem Sinne vereinfacht, dass an denjenigen Stellen im Bohrloch wo die lineare Bohrlochgeschwindigkeit abgeschätzt werden soll nur advektiver Transport berücksichtic̣t wird. Da keine Momente höherer Ordnung und entsprechende Zeitdifferentiale eingesetzt werden, ist die Methode der Direkten Integrale numerisch stabiler als die Methode der Partiellen Momente. 
In Kapitel 5 werden die oben beschriebenen drei Methoden auf synthetische Daten, welche mit einem numerischen 10-advektiven-diffusiven Transportsimulator (BORE) generiert wurden, angewendet. Basierend auf den Feldmessungen von Leuggern werden zwei synthetische Datensätzen erstellt: Testfall I besteht aus voneinander weit entfernten Zuflussstellen (hunderte von Metern) und nur geringfügig interferierenden Peaks, Testfall II aus sehr nahe gelegenen Zuflüssen (Dekameter), die schon zu sehr frühen Logging-Zeiten miteinander interferieren. Die verschiedenen Sensitivitäten und Einsatzbereiche der drei Methoden werden diskutiert und es kann gezeigt werden, dass der Simulationsinput im allgemeinen gut reproduziert werden kann. Insbesondere ergibt sich auch aus diesen Analysen, dass relativ früh gemessene Logging-Daten viel kritischere Informationen liefern als Logs welche zu späten Zeiten gemessen werden und dass die gesamte Testdauer ohne wesentiliche Informationsverluste auf 50-100 Std. reciuziert werden kann.

In Kapitel 6 werden die neu entwickelten Analysenmethoden auf Felddaten, welche 1987 in der Tiefbohrung Leuggern gemessen wurden, angewendet. Es kann gezeigt werden, dass die klassische Momentenmethode und die Direkte Integral Methode gute Inputparameter liefern für eine iterative "best-fit" Analyse mit einem Testsimulator wie BORE. Der Vergleich von unabhängig aus Packerversuchen bestimmten Transmissivitäten der Bohrung Leuggern mit den Resultaten der Methode der Partiellen Momente zeigt, dass die Unterschiede in den Resultaten beider Methoden im allgemeinen innerhalb eines Faktors 2 bis 3 (maximal Faktor 5) liegt. Diese Bereiche sind kleiner als die Fehlerbereiche von Packerversuchen allein; die Methode der Partiellen Momente ist aus diesem Grunde sehr erfolgsversprechend.

Im letzten Kapitel (Kapitel 7) werden die Implikationen der diskutierten Methoden für die Planung und Auswertung von Fluid-Logging Experimenten diskutiert. Es wird zudem ein umfassendes Analysenverfahren entwickelt, welches konzeptionelle Unsicherheiten, Datenqualität und Art der Loggingdaten (frühe oder späte Logging-Zeiten) explizit berücksichtigt. 


\section{RESUME}

Ce rapport décrit de nouvelles méthodes analytiques pour $I^{\prime}$ analyse quantitative de logs de conductivité électrique obtenus par diagraphie dans des forages en régime dynamique ("pumped wellhead conditions"). Les méthodes améliorent et complètent efficacement une procédure de test et une méthode de simulation par ajustement optimal présentée par Tsang et al. (1990). Les procédures de test et d'analyse permettent une localisation exacte $( \pm \mathrm{lm})$ de toutes les fractures présentant un débit qui sont intersectées par le forage, ainsi que le calcul de la transmissivité (et du potentiel) des fractures individuelles.

Les trois méthodologies présentées sont basées sur l'approche classique des moments qui est améliorée afin de permettre $l^{\prime}$ analyse quantitative de l'interférence des débits de multiple fractures dans le forage.

La section 1 est une discussion générale de la procédure de test et des équations utilisées pour l'analyse. Les relations du moment d'ordre 0 et du moment d'ordre 1 du débit d'une fracture dans un forage pendant le pompage sont obtenues. Celles-ci sont liées aux débits volumétriques totaux dûs puits au-dessous et en-dessus d'une zone présentant des débits dus à des fractures (section 2). Ces paramètres peuvent être utilisés directement pour évaluer le débit volumétrique et la concentration électrolytique du fluide de toutes les fractures qui n'interfèrent pas entre elles.

Les sections 3 et 4 présentent de nouvelles approches analytiques pour 1 'analyse des pics qui interfèrent entre eux. La méthode du moment partiel (section 3 ) est basée sur des quantités intégrales avec une structure similaire à celle des moments classiques. Par contre la mesure est effectuée entre deux pics successifs et non pas par pic considéré individuellement. La seule hypothèse faite dans le développement des équations fondamentales est celle d'un transport électrolytique uni-dimensiunnel advectif et dispersif à vitesse constante $v$ et dipersivité $k$ à $l$ 'intérieur de petits intervalles entre les fractures. La méthode permet théoriquement une détermination indépendante de $v$ et de $k$ à $l$ 'intérieur de $n^{\prime}$ importe quel intervalle de la section examinér et ceci quel que soit le temps, $t$, pendant 1 a diagraphie. Impliquant que la méchode $s^{\prime}$ applique également lorsque le débit et la concentration du fluide de 1 a fracture varient simultanément avec le temps. Les limites de la méthode du moment partiel sont principalement dues à des instabilités numériques qui apparaisent lorsque les temps deviennent élevés.

La méthode intégrale directe (section 4) se base sur uve approximation de la conservation de la masse prenant en compte l'information du moment d'ordre 0 lors de la phase initiale de la mesure. Le transport électrolytique est simplifié par rapport à l'équation mentionnée précédemment, car seul le transport advectif est considéré aux emplacements où la vitesse est estimée dans le forage.

Dans la section 5 les trois méthodes sont appliquées à des cas d'études synthétiques générés par un simulateur de transport advectif et dispersif à une dimension (BORE). Deux types de cas d'études différents sont considérés qui présentent des charactéristiques similaires à celles des 
données mesurées dans le forage profond de Leuggern effectué dans le noird de la Suisse. Les pics conducteurs du cas d'étude I, très espacés, présentent peu $d^{\prime}$ interférences. Le cas d'étude II, dont les fractures conductrices sont peu espacées, se charactérise par de fortes interférences. Une comparaison de la sensitivité des différentes méthodes est présentée. Les méthodes sont capables de reproduire les données avec une erreur inférieure à $50 \%$ et dans les meilleurs cas l'erreur est de 1 à $2 \%$. Les données correspondant à des temps faibles fournissent des informations beaucoup plus importantes que celles obtenues à des temps élevés. La durée du test peut être considérablement réduite (de 50 à 100 heures de diagraphie) sans perte d'information significative.

Dans la section 6 , les trois méthodes sont appliquées à des données réelles, mesurées en 1987, en provenance du forage profond de Leuggern. La localisation précise de toutes les fractures conductrices rencontrées par le forage est établie. La méthode classique des moments et la méthode intégrale directe peuvent servir de source de données à des simulations et des ajustements avec un simulateur tel que BORE. La méthode du moment partiel est capable de reproduire les débits mesurés dans les fractures du forage de Leuggern, obtenus indépendemment à l'aide de pompages avec packers (la différence maximale entre les deux méthodes est inférieure à $\frac{1}{2}$ ordre de grandeur). Cette erreur est du même ordre de grandeur que $l^{\prime}$ incertitude communément admise pour les tests de pompage avec packer

Les conséquences pour la planification des mesures sur le terrain et pour l'analyse des résultats sont décrites dans la section 7 . Les procédures de mesures devraient tenir compte des besoins des méthodes analytiques présentées. Une procédure d'analyse est developpée, qui prend en compte aussi bien les incertitudes conceptuelles que le type (à temps faibles ou élevés) et la qualité des données de conductivité. 


\section{SUMMARY}

The present report describes new methods for the quantitative analysis of dynamic fluid electrical conductivity logs measured in boreholes under production or free outflow conditions. The methods form powerful complements and extensions to a testing procedure and best-fit simulation approach previously presented by TSANG et al. (1990). The testing and analysis procedures allow an exact location of all fractures flowing under the given head drawdown and intersected by the borehole $(+/-$ $1 \mathrm{~m}$ in deep boreholes), as well as the calculation of the transmissivity (and head) of the individual flowing fractures.

The three methodologies presented in the present report start from the classical Moment approach applied to the 10 advection-diffusion equation, which is then further developed to allow for the quantitative analysis of multiple interfering fracture outflows into the borehole.

After a general discussion of the testing procedure and the governing equation used for analysis (Section 1), the zero'th and first moment relationships of a single fracture outflow inio a borehole during pumping are derived and related to the volumetric wellbore flowrates below and above an outflow zone (Section 2). These parameters can be used directly to evaluate the volumetric flow rate and the fluid electrolyte concentration of all non-interfering fracture outflows.

Sections 3 and 4 present new approaches for the analysis of interfering peaks. The Partial Moment Method (Section 3) is based or integral quantities with a similar structure as the classical moments, but measured between fracture outflows and not across. The assumption made in the development of the fundamental equations is that of 10 advective-dispersive electrolyte transport along the borehole with constant velocity, $v$, and dispersion, $k$, within the short intervals between fractures. The method allows, on principle, for an independent determination of $v$ and $k$ within any interval of the logged section and for any time, $t$, during logging. This implies that the method can also be used when both the fracture fluid concentration and the fracture flow rate are changing with time. The major limitation of the Partial Moment Method is related to numerical instabilities at late logging times.

The Direct Integral Methoc (Section 4) is sased on a mass balance approximation taking into account early time zero'th moment information and avoids the integral derivatives with their potential instabilities. The electrolyte transport is simplified with respect to the governing equation outlined above in the sense that only advective transport is considered at locations where the wellbore velocity is estimated.

In Section 5 the three methods are applied to synthetic test cases generated with a 10 advective-dispersive transport simulator (BORE). Two different types of test cases, with parameters similar to the field data measured in the Leuggern deep well of northern Switzerland, are considered: Test Case I with widely separated and only weakly interfering cutflow peaks, Test Case II with closely spaced and strongly interfering fracture outflows. The application shows the different sensitivities of the analytical methods considered. The methods are 
able to reproduce the input with an error smaller than $50 \%$ and for certain cases down to a difference of 1 or $2 \%$. It is shown that for the given parameters early time data give much more important information than late time data and that test duration can be reduced significantly (to 50 or $100 \mathrm{hrs}$ of logging, compared to $600 \mathrm{hrs}$ in the case of Leuggern) without losing relevant information.

In Section 6 the three methods are applied to real field data from the Leuggern deep borehole, measured in 1987. Besides precise localization of all flowing fractures intersected by the borehole, it can be shown that the Classical Moment Method and the Direct Integral Method form a valuable input and starting base for simulation and refinement with a simulator like BORE. By comparison with independently c'erived fracture flow rates from packer testing performed extensively in is:e Leuggern borehole, it can be shown that the Partial Moment Method is capable of reproducing the packer test results within a factor of 2 or 3 (greatest difference smaller than half an order of magnitude). These ranges lay within what is generally recognized as the uncertainty in packer testing.

Section 7 describes the implications for fieid experiment design and data analysis. The field experiment design should account for the needs of the analytical methods outlined. With respect to data analysis a comprehensive arialys is procedure that takes into account conceptual uncertainty, data quality, and type of conductivity logging data (early or late time) is deve?oped. 


\section{ACKNOWLEDGEMENTS}

Assistance and substantial support in the derivation of moment relationships from F. Ehlers and H. Hunziker ;- greatfully acknowledged. Discussions and cooperations with NAGRA personnel, especially S. Vomvoris and $P$. Bluemling are much appreciated. We would also like to thank S. Vomvoris, D. Gilby and $P$. Blümling for reviewing and commenting on the manuscript. The work is part of the NAGRA-DOE Cooperative (NDC-I) Project funded jointly isirough Nationale Genossenschaft für die Lagerung radioaktiver Abfaelle, Switzerland, and the Repository Transport and Technology Program, Office of Civilian Radioactive Waste Management, U.S. Department of Errergy through contract DE-ACO376 SF00098. 


\section{TABLE OF CONTENTS}

\section{ABSTRACT}

ZUSAMMENFASSUNG

RESUME

SUMMARY

ACKNOWLEDGEMENTS

TABLE OF CONTENTS

LIST OF FIGURES

LIST OF TABLES

NOTATION

1 INTRODUCTION

1.1 Description of Previous Work and Field Fluid Logging Procedure

1.2 Basic Assumptions and Conceptual Model

1.3 Quantification of Transmissivity from the Results of Fluid Conductivity Logging

2 THE CLASSICAL MJMENT METHOD

2.1 Background

2.2 Zero'th Moment Relationships

2.3 First :loment Relationships

3 THE PARTIAL MOMENT METHOD

3.1 Introduction

3.2 Derivation of Partial Moment Equations

3.3 Discussion of Partial Moment Equations

4 THE DIRECT INTEGRAL METHOD

4.1 Early-Time Non-interfering Peaks

4.2 Interfering Peaks

4.3 Transient Fracture Outflow

5 APPLICATION OF MOMENT METHODS TO SYNTHETIC TEST CASES

5.1 Test Case Description

5.2 Apni ication of the Classical Moment Method

5.3 Application of the Partial Moment Method

5.4 Application of the Direct Integral Method 
6 APPLICATION OF MOMENT METHODS TO FIELD DATA AND COMPARISON WITH PACKER TEST RESULTS

6.1 Description of the Leuggern 1987 Fluid Logging and Data Conversion 6.2 Application of Moment Methods to the Leuggern 1987 Data

7 IMPLICATIONS FOR FIELD EXPERIMENT DESIGN AND DATA ANALYSIS

7.1 Field Experiment Design

7.2 Data Analysis Procedure

7.3 Conclusions

8 REFERENCES 


\section{LIST OF FIGURES}

Fig. 2-1: Mass balance relationships for a single fracture outflow with saline fluid flowing into de-ionized well bore fluid

Fig. :-2: Mass balance relationships for a single fracture outflow with low saline fluid flowing into brine

1 q. 5-1: Fluid electrical conductivity logs for synthetic test case I

Fị̣. 5-2: Fluid elecirical conductivity logs for synthetic test case II

iig. 5-3: Zero Partial Moment versus time for synthetic test case I

Fig. 5-4: Volumetric wellbore flow races as a function of time, examples cases from 2 intervais of synthetic test case I

Fig. E-5: Zero Partial Momen: versus time for synthetic test case II

Fig. 6-1: Geology and borehole characteristics of the Leuggern borehole

Fig. 6-2: Plot of the 1987 fluid logs measured in the Leuggern borehole

Fig. 6-3: Zero Partial Moment versus time for Leuggern 1987 field data

Fig. 7-1: Fluid logging analysis approach 


\section{IST OF TABLES}

Table 5-1: Characterization of Synthetic Test Cases

5-2: Comparison of Simelation Input and Classical Moment Output for Synthetic Test Case I

5-3: Comparison of Simulation Input and Classica? Moment Out.put for Synthetic Test Case II

5-4: Comparison of Simulation Input and Partial Moinent Output for Synthetic Test Case I

5-5: Comparison of Simulation Input and Partial Moment Outpui for Synthetic Test Case II

5-6: Conparison of Simulation Input and PRE Output for Synthetic Test Case I

5-7: Comparison of Simulation Input and PPE Output for Synthetic Test Case II

6-1: Comparison of Mass Rates derived from Packer Testing/ Sampling and Zero Moment Results

6-2: Comparison of Packer Test and Partial Moment Results for the Leuggern field data

6-3: Comparison of Packer Test and PRE Results for the Leuggern field data 


\section{NOTATION}

solute concentration

$C_{A}$ solute concentration in the wellbore at point $A$

$C_{c}$ constant solute concentration at semi-infinite tube model boundary

$C_{i}$ solute concentration of the fracture $i$

$C_{c}$ background solute concentration in the wellbore

$C_{r r}$ cecond derivative of concentration with respect to $r$

$c_{t}$ first derivative of concentration with respect to $t$

$c_{x}$ first derivative of concentration with respect to $x$

$i_{x x}$ second derivative of concentration with respect to $x$

D coefficient of molecular diffusion

h piezometric htad

$h_{0}$ initial piezometric head prior to pumping

$I_{n}(t) n$-th Partial Moment (being a function of $t$ )

$I_{t}$ first derivative of Partial Moment with respect to $t$

$k$ coefficient of dispersion

$\lambda$ advection length

$M_{n}(t) n-t h$ (Classical) Moment (being a function of $t$ )

$M_{t} \quad$ first derivative of Classical Moment with respect to $t$

Q volumetric flow rate in the wellbore

$a_{1}$ volumetric outflow rate of fracture $i$

$r$ wellbore radius

$R$ radial coordinate in a flow system

- electrical conductivity

$s_{w}$ effective drawdown in the well

S storativity

$S_{s} \quad$ specific storage 


\section{$-x v i i i-$}

$S_{f}$ inflow point source term

$t$ time

T transmissivity

$\tau \quad$ kinematic viscosity

$v$ linear (mean) velocity in the wellbore

$w$ volumetric flow rate at the bottom of the well 


\section{INTRODUCTION}

\subsection{Description of Previous Work and Field Fluid Logging Procedure}

A new approach to the determination of outflow parameters (flow rate and salinity of fracture fluid) from fractures intercepted by a wellbore was proposed by TSANC and HUFSCHMIED (1988) and TSANG et al. (1990). The approach involves first flushing the wellbore with deionized water and, logging the values of fluid electric conductivity within the borehole as a function of depth for varicus times while producing. The temporal changes of fluid conductivity logs can be used in a matching procesiure to obtain fracture outflow parameters. The approach was successfully applied to 2 sets of data obtained in 1985 and 1987 in the Leuggern well by Nagra, Switzerland.

In 1989 Nagra conducted several fluid logging experiments in the Siblingen well. One experiment was performed with brine as the flushing (or background) fluid, resulting in reverse relationships ("negative" peaks) from the ones described above. Such relationships are especially important when drilling with clay based drilling muds that cannot be replaced by de-ionized water prior to logging (e.g. NAGRA 1989).

Previous reports presented an indirect or iterative procedure for analyzing a time sequence of wellbore electric conductivity logs in order to obtain outflow parameters of fractures intercepting the borehole (TSANG et al. 1990), and for this purpose a code, called BORE, was developed to simulate borehole fluid conductivity profiles given these parameters (HALE and TSANG, 1988). The present report describes new direct methods for analyzing electric conductivity logs. These methods are based on the temporal variation of moments over entire outflow peaks or sections of the conductivity profiles and allow for a quick and in most cases precise estimation of all fracture parameters of interest.

The combination of direct solution methods with the numerical modeling code, BORE, forms a more complete system for estimating fracture outflow parameters and designing fluid logging tests than was presented in the previous work.

\subsection{Basic Assumptions and Conceptual Model}

Let us assume a vertical wellbore being intersected by subhorizontal fractures and other zones with a higher permeability than that of the matrix, the water pressure (or head) in the well is lowered by pumping to below that of the formation fluid conducting features. The electrolytes bearing formation fluid will then enter into the wellbore and mix with the originally de-ionized water in the well.

Because the electrical conductivity is directly related to the electrolyte concentration of a fluid (see section 6 for details), an electrical conductivity peak will appear at each outflow location, given that the nutflowing formation water has a salinity (or electrolyte 
concentration) greater than the borehole fluid. These peaks will grow with time and electrolytes will migrate up the borehole due to advection and dispersion and down the borehale due to free convection and dispersion. As one proceeds up the borehole, the volumetric flow will increase as each flowing zone contributes an amount depending on the transmissivity and static head of each feature.

The fluid of a given concentration or the electrolytes at the outflow location will move away from this point 'sriven by a variety of processes (advection, diffusion, gravity and temperature-driven processes). In this report only one-dimensional flow and transport by advection and dispersion will be considered in the analysis.

Flow and transport in the wellbore will be approximated by flow in a tube of constant radius. For the flow to be below the turbulence regime the Reynold's number, Re, must be smaller than the critical value of about 2,000 (e.g., ROBERTSON and CROWE, 1985). Using the relationship:

$$
\operatorname{Re}=\frac{2 v r^{1)}}{r}
$$

with $r=$ wellbore radius, $v=$ average (linear) velocity, and $\gamma=k$ inematic viscosity, the resulting maximum Re-value for the Leuggern 1987 logging $\left[r=0.08 \mathrm{~m}, v_{\max }=3 \mathrm{E}-3 \mathrm{~m} / \mathrm{s}, \gamma_{\min }=5 \mathrm{E}-7 \mathrm{~m}^{2} / \mathrm{s}\right]$ is 1,050 , i.e. below the turbulence regime. Similar Re-values result for the other borehole fluid electrical conductivity logging experiments performed in deep boreholes in the past by Nagra. Tierefore, laminar flow relationships can be used throughout this report.

The general governing equation for laminar flow in a pipe of radius $r$ with a parabolic velocity distribution and longitudinal and radial diffusion can be expressed by (e.g., TAYLOR, 1953):

$$
C_{t}+2 v\left(1-R^{2} / r^{2}\right) C_{x}-D\left(C_{R R}+C_{R} / R+C_{x x}\right)=0
$$

where $D$ is the coefficient of molecular diffusion, $R$, a radial coortinate and $x$ is measured along the tube's axis (positive in the downwell direction), the subscripts $t, x$ and $R$ denote derivatives with respect to these parameters.

The widely used simplification of (1-1), namely

$$
C_{t}+v C_{x}-k C_{x x}=0
$$

with

$$
k=\frac{r^{2} v^{2}}{48 D} \text { (= Taylor dispersion) }
$$

1) for notation throughout this report see the section Notation at the beginning of the report 
holds under two assumptions. These can be expressed by (TAYLOR 1953; 1954):

(i) $4 \lambda / r \gg r v / D$

$$
6.9 \ll r v / D
$$

where $\lambda$ is the longitudinal extent of the region in which $C_{x}$ is appreciable (advection length).

Assumption (i) can also be written as:

$$
\lambda / v \gg r^{2} /(4 D)
$$

and describes the case, where radial diffusion dominates over axial convection. It corresponds to the time necessary for radial concentration differences to be reduced by radial diffusion compared to the time required for longitudinal convection to cause appreciable radial concentration variations.

If ratios of 10:1 (TAYLOR, 1954) are permitted between the terms of the inequalities in (1-4) and (1-5), the following advection length $\lambda$ is required for $(1-2)$ to hold theoretically:

$$
\lambda=690 \mathrm{r} / 4
$$

corresponding to a distance of $13 \mathrm{~m}$ in the case of the Leuggern borehole, and to $8 \mathrm{~m}$ in the case of the Siblingen borehole (for distances between fracture outflows see e.g. Table 6-1).

For a typical average flow velocity range of $6 \cdot 10^{-6}$ to $6 \cdot 10^{-5} \mathrm{~m} / \mathrm{s}$ (Sections 5 and 6 ), this distance corresponds to a period of about 0.5 to 55 hours. However, because of the radial mixing effects of the logging tool and the nature of tracer inflow into the borehole (ring type source compared to initially constant concentration field as in TAYLOR, 1953), it can be assumed that assumption ( $i$ ) holds even at earlier times.

Assumption (ii) relates to the importance of longitudinal molecular diffusion. This process can be neglected as long as:

$$
D \ll \frac{r^{2} v^{2}}{480}
$$

or the equivalent inequality (1-5) holds. Assuming again a ratio of $10: 1$ for the inequalities (TAYLOR, 1954), the mean velocity $\vee$ must have at a minimum the value:

$$
v=69 \mathrm{D} / \mathrm{r}
$$

corresponding (for a diffusion coefticient of $10^{-9} \mathrm{~m}^{2} / \mathrm{s}$ and a radius of $0.07 \mathrm{~m}$ ) to about $10^{-6} \mathrm{~m} / \mathrm{s}$. This requirement is usually fulfilled. 
Equation (1-2) is the basic equation used throughout the present report to describe the electrolyte transport in the well. Taylor's approximation of the dispersion might not be appropriate in most cases, because of the nature of the tracer inflow into the borehole and measuring tool related effects. For this reason, $k$ is allowed to be a fitting parameter in BORE simulations and is treated as an unknown in the moment approaches derived in the present report.

\subsection{Quantification of Transmissivity from the Results of Fluid Conduc- tivity Logging}

The results of the fluid conductivity logging (i.e. the volumetric flux produced from each permeable zone) can be combined with other observations made during the time of pumping in order to calculate the transmissivity of each of the permeable zones. These calculations make use of the basic equation describing the unsteady flow of water to a well in a confined aquifer and analytical solutions to this equation given certain assumptions. Essentially, each of the individual influx values can be treated as a small-scale pump test which can be readily analyzed using traditional well-testing techniques.

The general solution of the unsteady flow of water to a well in a confined aquifer may be written after THEIS (1935).

$$
s_{w}(r, t)=h_{0}-h(r, t)=\frac{q}{4 \pi T} W(u)
$$

where

$$
\begin{aligned}
& W(u)=\text { well function of } u \\
& u=\frac{r^{2} S}{4 T t}
\end{aligned}
$$

This equation assumes that the wellbore discharge rate, $q$, is constant.

For small values of $u(<0.01)$, which corresponds to a small radius or a large time, the well function may be approximated by (COOPER and JACOB, 1946):

$$
s_{k}(r, t)=\frac{q}{4 \pi T} \ln \left(\frac{2.25 T t}{r^{2} s}\right)
$$

This equation has been used in the past to determine iteratively the transmissivities of the individual zories identified in the fluid conductivity logging. It is useful to enumerate the assumptions involved in using the Cooper-Jacob approximation of the Theis solution:

a) The aquifer is infinite, homogeneous and isotropic. 
b) The flow in the aquifer is radial and horizontal.

c) The head in the aquifer prior to pumping $\left(h_{0} ;\right.$ is uniform.

Sensitivity studies have shown, that for typical fluid logging parameter rarges, the calculated transmissivity is not sensitive to the storativity, the oniy parameter in equation (1-10) that is not determinable. The head difference per outflow zone can either be approximated to be constant (when $h_{0}-h$ is big compared to the head differences between the fracture zones) or calculated if two sets of logging runs under different pumping rates are available. 


\section{THE CLASSICAL MOMENT METHOD}

\subsection{Background}

The general definition of the $n$-th moment of a concentration distribution along the axes $x, c(x)$, and centered around the origin is given by (e.g. FISCHER et a1., 1979):

$M_{n}(t)=\int_{-\infty}^{\infty} x^{n} C(x, t) d x$

ARIS (1955) was the first to relate the moments of a pulse injection into a tube (a+:acer slug) to the hydraulic parameters in the tube: velocity, $v$, and dispersion, $k$. He related the zero'th moment of a single tracer slug to the slug mass, the first moment to the sliug velocity and the second moment to the dispersion in the tube. The present section discusses similar relationships for the case of continuous mass inflows into a borehole or cylindrical tube (equivalent to fracture outflows).

In the case of multiple outflows it is importani to note 'iat the peaks are not allowed to overlap (otherwise inflow specific moments can no longer be derived). This restriction can in part be overcome by using only early time conductivity logs with no, or limited, cverlap.

The integrals described in the following are evaluated numerically with a code called MOMENT (LOEW and CALMBACH, 1990). The integration performed is numerically based on the trapezoidal rule, i.e. with linear interpolation between the actual measurement points.

\subsection{Zero'th Moment Relationships}

The zero'th mc ent of a single outflow peak located between $L_{0}$ and $L$ is defined by (compare Fig. 2-1):

$M_{0}(t)=\int_{L}^{L_{0}}\left[C(t)-C_{0}\right] d x$,

where $C$ is the electrolyte concentration, $x$ the depth measured along the borehole with $x=0$ at the ground surface, and $C_{0}=$ initial (background) salinity in the well prior to pumping. The integration boundaries, $L_{0}$ (lower boundary with respect to depth) and $i$ (upper boundary), are those locations respectively below and above the outflow peak where the electrolyte concentration reaches background value for all logging times.

The zero'th moment as defined above (with $C(L)=C\left(L_{0}\right)=$ const. and $C_{x}(L)=$ $\left.C_{x}\left(L_{0}\right)=0\right)$ can be related to the fracture outflow parameters $q_{i}$ and $C_{i}$ through the following mass balance relationship within the section $L$ to $L_{0:}$ 
$M_{0}(t) \pi r^{2}=-t\left(q_{i}+Q\right) C_{0}+t Q C_{0}+t q_{i} C_{i}$,

where $r$ = wellbore radius. The first term on the right-hand side corresponds to the mass leaving the system through the upper boundary $10-$ cated at $x=L$, the second term to mass entering the system through the lower boundary lucated a' $x=L_{0}$, and the third term to the mass outflow from the fracture up to time $t$. Equation (2-2) holds for small $t$, or as long as the conceritration at the integration boundaries remains at background concentration $\mathrm{C}_{0}$.

In case of low background salinity (i.e. for flushing with de-ionized water) and relatively high fracture mass production, the first two terms on the right-hand side of equation (2) can be dropped. Equation $(2-2)$ then simplifies to:

$M_{0}(t) \pi r^{2} \approx t q_{i} C_{i}, \quad\left(\right.$ for $\left.C_{0} \rightarrow \infty\right)$

stating that the zero'th moment is a direct measure of the mass outflow of a single non-interfering fracture. Therefore the zeroth moment can be used directly to investigate the mass or mass rate released by a single fracture and to perform simple mass balance calculations. It is also worth mentioning that this relationship is independent of the governing equation describing the mass transport of the solute as long as the 10 approximation holds.

In the case of high background salinity (i.e. fur flushing with brine) equation (2-2) can only be simplified by combining the terms:

$M_{0}(t) \pi r^{2} \approx t q_{i}\left(C_{i}-C_{0}\right)$,

implying that the mass production of a single fracture can no longer be expressed as a simple function of the zero'th moment. Mass balance calculations in this case require additional information. This can either be the knowledge of $q_{i}$ (assuming the measured pumping rate corresponds to the fracture volumetric outflow rate), or $C_{j}$ (from water sampling) or information from higher order moments (see section 2.3).

An additional implication of equation (2-5) is that the zero moment quantity as defined above is in fact a measure of the concentration difference between the fracture and the wellbore fluids. In the case of a large concentration difference (eg. de-ionized water flowing into brine) the zero moment quantity (and equation (2-5)) will therefore nc longer be a suitable measure of the absolute value of the outflow concentration and mass released by the fracture, since $C_{i} \ll\left|C_{i}-C_{0}\right|$ and its value may be withir the error of meisurement. Additional implications of equation (2-5) ars discussed in section 7.1.

Besides mass balancing, our first priority parameter of interest, $q_{i}$, can be estimated in both cases from the zero'th moment relationships as long as $\left(C_{i}-C_{0}\right)$ can be estimated sufficiently well. Precise determinations of $q_{i}$ require additional information as first order moments. 
$-8-$

2.3 First Moment Relationships

The first moment of a single outflow peak centered around the outflow position $x_{1}$, with $L_{0}>x_{1}>L$, is defined by (compare Fig. 2-1):

$M_{1}(t)=\int_{L}^{L_{0}}\left(x-x_{1}\right)\left(c-C_{0}\right) d x$,

with the parameters being defined as for equation (2-2).

For a constant dispersion coefficient over the fracture. outflow peak, $k$, variable well bore velocities on the upstream $\left(v_{-}\right)$and downstream $\left(v_{+}\right)$ side of the outflow (ie. respectively below and above the outflow), and variable concentration, the time derivative of the first moment is given by:

$$
\begin{aligned}
& x_{i} \quad L_{0} \\
& M_{1 t}=\int\left(x-x_{1}\right) C_{t} d x+\int\left(x-x_{f}\right) C_{t} d x \text {. } \\
& x_{i} \\
& x_{i} \quad L_{0} \quad x_{i} \\
& M_{1 t}=k \int\left(x-x_{1}\right) C_{x x} d x+k \int\left(x-x_{1}\right) C_{x x} d x-v_{+} \int\left(x-x_{1}\right) C_{x} d x \\
& \text { L } \\
& -v_{-} \int\left(x-x_{j}\right) C_{x} d x \\
& x_{i} \\
& \text { L } \\
& x_{i}
\end{aligned}
$$

The integrals can be partially evaluated to give:

$$
\begin{array}{cccc}
x_{i} & L_{0} & x_{i} & L_{0} \\
M_{1 t}= & -k \int C_{x} d x & k & \int C_{x} d x+v_{+} \int C d x+v_{-} \int C d x . \\
L & x_{i} & L & x_{i} \\
+ & v_{+}\left(L-x_{i}\right) C(L)+v_{-}\left(x_{i}-L_{0}\right) C\left(L_{0}\right)
\end{array}
$$

(Remembering that the derivative $C_{x}=0$ at $x=L$ and $x=L_{0}$, section 2.2.)

If we define zeroth moments for the up -and downstream side of an outflow separately as follows: 


$M_{0+}=\int_{L}^{x_{i}}\left(C-C_{0}\right) d x$ and $M_{0 .}=\int_{x_{1}}^{L_{0}}\left(C-C_{0}\right) d x$

and assuming continuity of the $c(x, t)$ function at $x=x_{1}$, equation (2-9) simplifies to (remember that $C$ at $L_{0}=C$ at $L=C_{0}$, section 2.2 ):

$M_{1 t}=v_{+} M_{0+}+V_{-} M_{0 .}$.

When the wellbore radius arid either $v_{+}$or $v_{-}$are known this equation can be applied to determine the fracture outflow rate. $v_{-}$is known for each peak when all fracture outflows are analyzed sequentially from the bottom of the well to the top (assuming zero flux below the deepest fracture). $v_{+}$is known foi each peak when the outflows are analyzed from the top of the logged section to the bottom (assuming the pumping rate corresponds to the total production of the logged section).

The assumptions made in the derivation of equation (2-11) art:

1) For $L<x<x i: C_{t}=k C_{x x}-V_{+} C_{x}$.

2) For $x i<x<L O: C_{t}=k C_{x x}-V_{-} C_{x}$.

3) $\quad C(x, t)$ is continuous at $x=x i$

4) $\quad C(L, t)=C\left(L_{0}, t\right)$ and $C_{x}(L, t)=C_{x}\left(L_{0}, t\right)=0$

From 1) and 2) it follows that the dispersion, $k$, is treated as constant. In the analysis of field data performed until present (e.g. TSANG et al. 1990) the best-fit approaches with the numerical simulator BORE were done with constant dispersion values. The fits were not improved by scaling the dispersivity for velocity (hydrodynamic dispersion) or velucity squared (Taylor dispersion). Therefore, especially within the relatively short intervals considered, the assumption of constant dispersion is jus? ifiable. Alternatively, second moment relationships (not derived in the present report) could be used to account for variable dispersion values across a fracture outflow.

Also from 1) and 2) it follows, that $v_{-}$and $v_{+}$, and therefore the volumetric fracture outflow $q_{i}$, are constant with time. This assumption could be overcome by selecting only a limited amount of consecutive conductivity logs (eg. 3) that cover a time period when the temporal changes in $q_{\text {, }}$ are small.

Based on field experience from the Siblingen and Leuggern well, the main and most important parameter that is often not constant in time is the fracture outflow concentration $C_{i}$. However, such an assumption is not made in the derivation of equation $(2-11)$ and, therefore, the methodology can even be applied in case of time varying fracture outflow concentrations. 


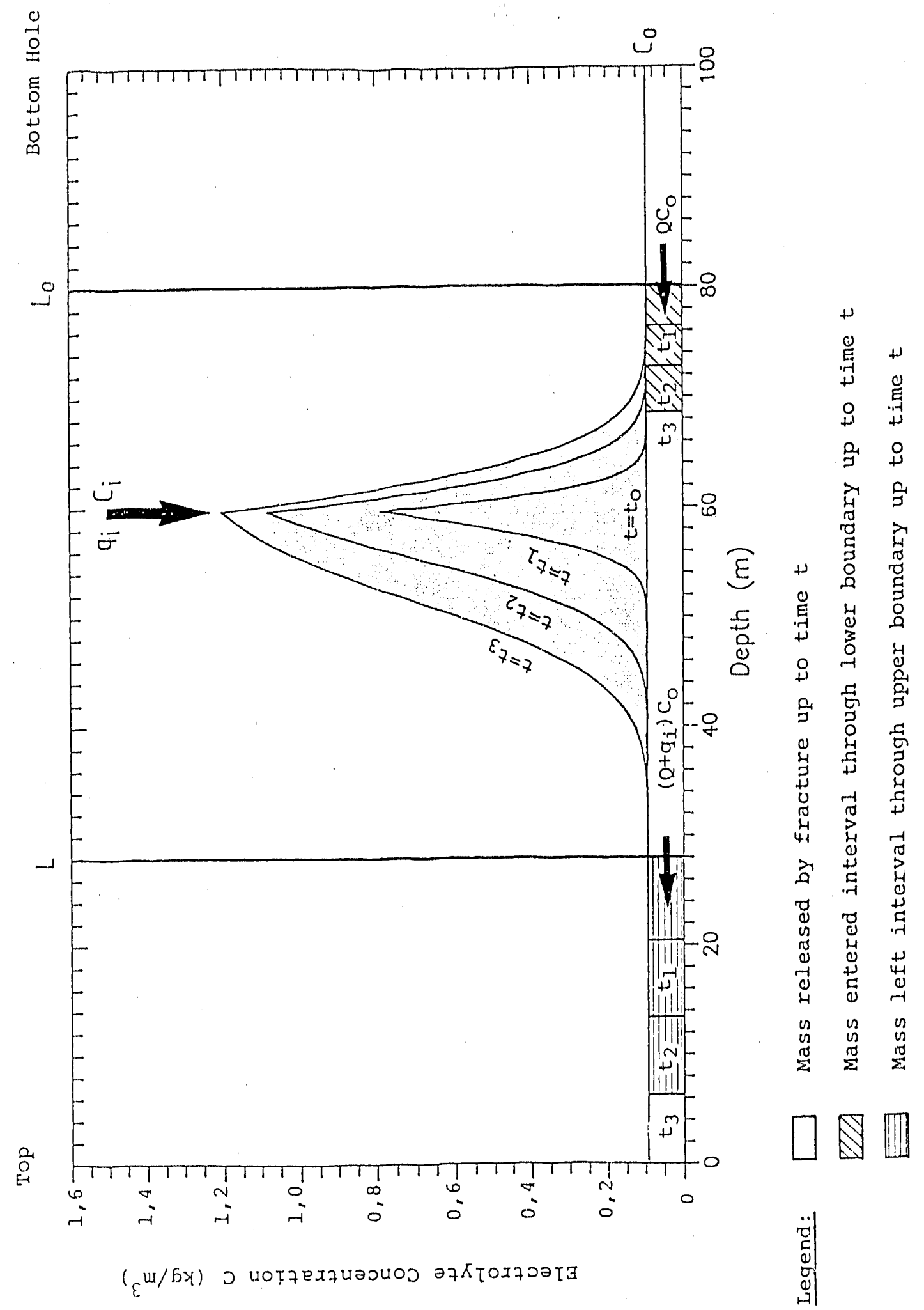

Fig. 2-1: Mass balance relationships for a single fracture outflow with saline fluid flowing into de-ionized wellbore filuid. The "masses" indicated in the legend are in fact masses per cross-sectional area. 


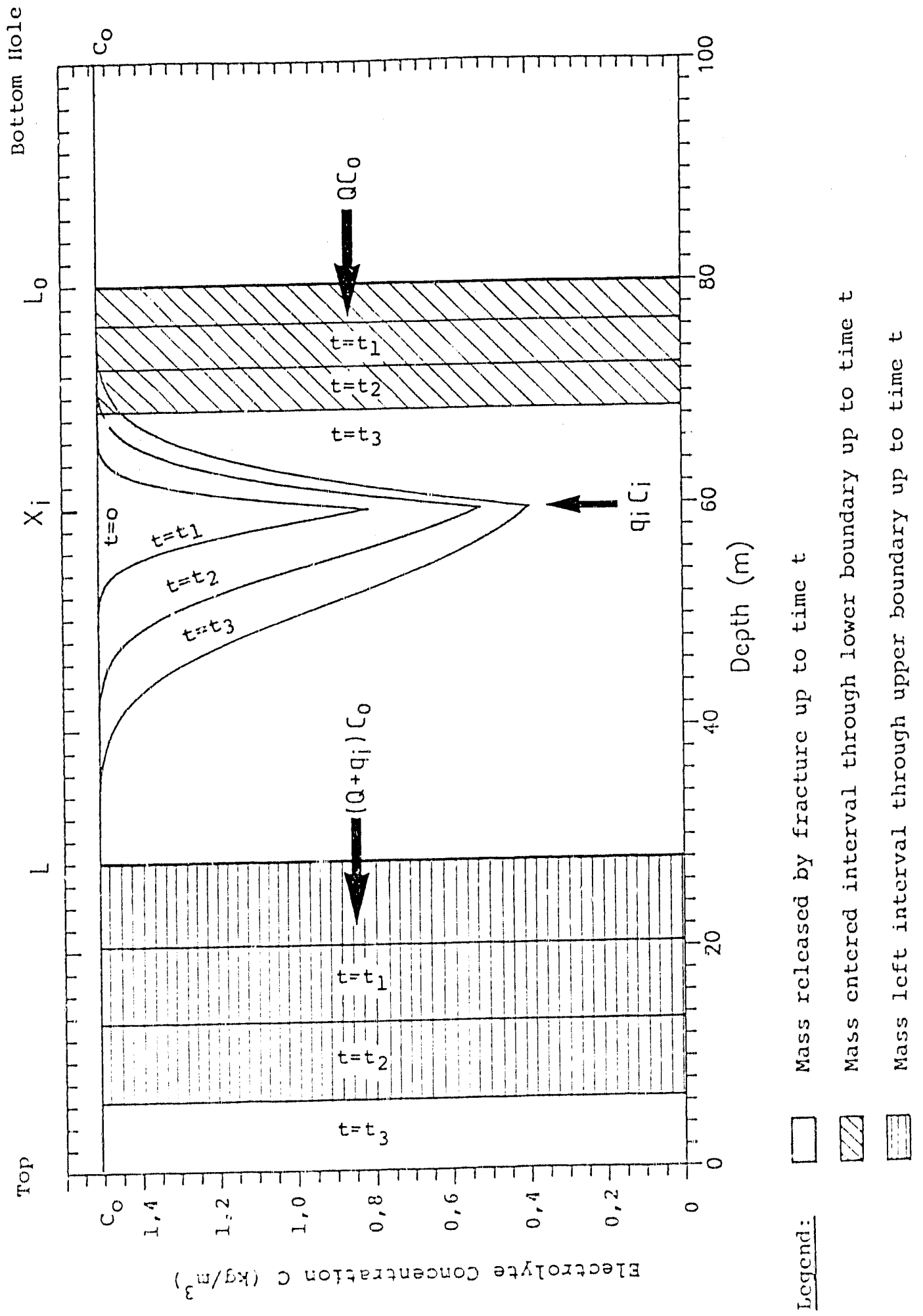

Fig. 2-2: Mass balance reiationships for a singie fracture untfiuw with low saline fluid flowing into brine. The "masses" indicated in the legend are in fact masses per cross-sectional area. 


\section{THE PARTIAL MOMENT METHOD}

\subsection{Introduction}

Classical moment methods can only be applied to individual, non-interfering peaks and therefore this method is very limited in application with regards to borehole fluid logging data. The Partial Moment Method (and the Direct Integral Method, see section 4) has been derived to overcome this major restriction but to provide nevertheless a quick and straightforward analysis tool. The method outlined in this section is called "Partial Moment" because quantities are defined in the same integral forms as the classical moments but with integration limits that encloses only a part of a fracture outflow peak. The approach allows the theoretical eva'uation of the local borehole fluid velocity and dispersion at any point along the borehole and for any time during logging.

A11 quantities and equations described in section 3 are programmed in an interactive code called MOMENT (LOEW and CALMBACH, 1990). The differentiations outlined in the following are performed through fle,ible least squares fitting of poiynomials through a specifiable number of data points and exact differentiation of the fitted lines. The incegrations (see paragraph 2.1) are likewise performed on the fitted polynomials.

\subsection{Derivation of Partial Moment Equations}

The function $c(x, t)$ is subject to the advection-diffusion-equation (see section 1):

$C_{t}+v C_{x}-k C_{x x}=0$

with velocity $v$ and dispersion $k$,

$A \leqslant x \leqslant B, 0 \leq t<\infty$

The actual range of $x$ may be larger (i.e. extending from fracture outflow to fracture outflow), the restrictions are assumed to be such that $v$ and $k$ are constant within these bounds. The objective is to derive relationships for $v$ and $k$ given $c(x, t)$ for $a l l x$ and $t$.

The following quantities are defined:

$1=B-A$

B

$I_{c}(t)-\int C(x, t) d x$
The Zern'th Partial Moment

The distance between the integration boundaries 


\author{
B \\ $I_{1}(t)=\int(x-A) C(x, t) d x$ \\ The First Partial Moment \\ A
}

Equation (3-1) can be integrated with respect to $x$, thus

$\int c_{t} d x=k \int c_{x x} d x-v \int c_{x} d x$

For constant integration limits the order of differentiation with respect to $t$ and integration with respect to $x$ on the left-hand side may be reversed to yield:

$\frac{d}{-} \int c d x=k \int c_{x x} d x-v \int c_{x} d x$

$d t$

Evaluating th? integrals over the specified range of $x$ yields:

$I_{\text {ot }}=-v\left(C_{B}-C_{A}\right)+k\left(C_{x B}-C_{x A}\right)$

Multiplication of equation (3-1) hy $(X-A)$ prior to integration yield:

$I_{, c}=-v\left(1 C_{B}-I_{0}\right)+k\left(1 C_{x B}-C_{B}+C_{A}\right)$,

with $I_{n t}$ denoting the time lerivative of the $n$-th Partial Moment, $C_{A}$ the measured (or interpolated) concentration at point $A$, and $C_{x A}$ t'ie space derivative (slupe) à point $A$.

In equations (3-7) and (3-8), all quantities except $v$ and $k$ may be directly calculated from the observed concentration profiles over time.

\title{
3.3 Discussion of Partial Moment Equations
}

Solving equations $(3-7)$ and $(3-8)$ for the wellbore velocity $v$ results in:

$V=\frac{I_{0 t}\left(1 C_{\times B}+C_{A}-C_{B}\right)-I_{1 t}\left(C_{\times B}-C_{\times A}\right)}{\left(C_{A}-C_{B}\right)\left(1 C_{\times B}+C_{A}-C_{B}\right)+1 C_{B}\left(C_{\times B}-C_{\times A}\right)-I_{0}\left(C_{\times B}-C_{\times A}\right)}$

When the outflow conditions (i.e. $q_{i}$ and $c_{i}$ ) are invariant in time, the concentrations at the integration boundaries, the slopes at the integration boundaries and the Partial Moments will converge to constant values (compare Fig. 5 and 11 in TSANG ot a?. 10on). This holds for single as well as for multiple inflows, although for multiple inflows these time functions will not be smooth when peaks start to interfere. 
The convergence implies, that:

$\lim I_{\text {ot }}=\lim I_{1 t}=0$.

$\lim _{t \rightarrow \infty} I_{t \rightarrow \infty}$

Because $v$ in the cases considered is not zero, it follows that for large $t$ both the denominator and the numerator in (3-9) converge to zero. This means that, for large times $t$ (when $I_{\text {ot }}$ and $I_{1 \tau}$ become smali), numerical errors will arise in the determination of $v$. For the case of time invariant boundary conditions, however, the system is over-determined in the sense that for every observation period (time used to calculate the time derivatives) an individual $v$ (and $k$ ) value can be derived. This allows us to select suitable values or to calculate weighted means.

Based on the relationships outlined above, the following criteria can be used for this selection (or weighting) of velocity values:

- Larger $I_{\text {ot }}$ and $I_{1 t}$ values (i.e. fast moment changes) provide better $v$ estimates than small values.

- The calculated time derivatives of the Partial Moments are in general more precise when the $I_{0}$-versus-time and the $I_{1}$-versus-time functions are smooth. Therefore $v(t)$ values for times when peaks start to interfere (and $C_{A}$ and $C_{B}$ "jump" in magnitude) should be weighted less than values for times when the moment-versus-time functions behave smoothly.

- Bigger (longer) integration intervals provide better $v$ estimates than short intervals.

A further potential application of the Partial Moment Method is to the case of time varying input functions (especially fracture outflowconcentrations), as long as the parameters $v$ and $k$ can be approximated to be reasonably constant within an observation period. This case would have bien extremely difficult to analyze by a manual fitting approach with a lost simulator because of the large number of unknown variables affecting the fit. In summary the limitations of the Partial Moment Method to situations with time varying input functions are related to:

- the change in $v$ and $k$ during the observation period

- the quality of the data (measurement noise)

- the suitability of the governing transport equation

- the exactness of the time differentials.

The last three conditions also hold for the time-invariant case described previously. Again it should be noted, that, as in the case of equation $(2-11)$, the fracture fluid concentration does not have to be constant with time. 


\section{THE DIKECT INTEGRAL METHOD}

In this section we present an additional method that employs time integrals. It is complementary to the methods described above.

\subsection{Early-Time Non-interfering Peaks}

Given a borehole electric conductivity profile $\sigma(x, t)$ measured at a given time, $t$, the area under each peak at $x_{i}$ can be obtained numerically. In case of small background concentration, this area - or the zeroth moment - can be simply related to $q_{i} c_{f}$, where $q_{i}$ is the flow rate in $\mathrm{m}^{3} / \mathrm{s}$ and $C_{j}$ is the concentration of the inflow fluid in $\mathrm{kg} / \mathrm{m}^{3}$ (see equations $(2-2)$ and $(2-4))$ :

$$
\int_{x_{i}-\delta_{1}}^{x_{i}+\delta_{2}} \pi r^{2}\left(\sigma(x, t)-\sigma_{0}\right) d x=\alpha\left(q_{i} C_{i}\right)\left(t-t_{i}\right)
$$

where $\delta_{1}$ and $\delta_{2}$ are appropriate distances for bracketing the peak, $r$ is the mean wellbore radius over this interval, $\alpha$ is a coefficient that relates salinity to electric conductivity and $t_{i}$ is the time at which the fracture fluid began flowing into the borehola. This equation assumes that both $q_{i}$ and $C_{i}$ are constant with time. Also the integral on the left-hand side should be evaluated only for relatively early times, before the adjacent peaks overlap significantly.

Equation (4-1) can be applied to a set of conductivity profiles, and a plot of $f\left(\sigma-\sigma_{0}\right) d x$ against $t$ will give as the slope $\left(a / \pi r^{2}\right) q_{i} C_{i}$ and as the intercept the time $t_{i}$ when the fracture fluid started to flow into the borehole.

\subsection{Interfering Peaks}

At very large times the peaks interfere fully and concentration values along the wellibore reach steady state with their values given by simple mixing theory (TSANG et al. 1990). Then in principle, once $t_{i}$ and $q_{i} C_{i}$ are obtained for each peak, one can apply these late-time results to calculate the flow rate of the particular inflow point. Thus, from careful measurements of early-time and late-time log data, one can obtain all the inflow flow rates in a simple and straightforward way. These results are not sensitive to moderate variations of wellbore dispersion. Note also that although the short-term results depend on wellbore radius, the late-time results are independent of it.

If the very late-time results are not available, as is usually the case in field experiments, the following method can be used to obtain a good first estimate of flow rate $q_{i}$ from each peak. Consider a wellbore with several inflow points, each with a flow rate $q_{i}$, concentration $C_{i}$, and position $x_{i}$. The initial salinity in the well is $c_{0}$, and the inflow at the bottom of the well is $w$. Position is measured as depth below the surfuce. 
Let $x_{0}$ be a reference point near the bottom of the well, upstream from the first fracture inflow point (i.e. further down the borehole), and let $X$ be a point up the well from $x_{0}$. At $X_{0}$ the conductivity is assumed constant and equal to the initial conductivity $\sigma_{0}$. The problem then is to obtain the flow rate $Q_{x}$ at the point $X$ in the wellbore in terms of the electric conductivity $\log$ at different times. $Q_{x}$ is the sum of all of the $a_{i}{ }^{\prime} s$ between $x_{0}$ and $x$, plus the inflow, $w$, from the bottom of the well at $x_{0}$. To simplify the discussion without loss of generality, $w$ will be assumed to be zero in the analysis that follows. Note that taking the difference of two values of $Q_{x}$, one upstream from an inflow point and one downstream from the inflow, will yield a value for $q_{i}$ at that inflow.

If it can be assumed that all inflows initiate at the same time $(t=$ $0)$, then $\bar{c}_{x}$, the mean concentration in the wellbore over the section between $x_{0}$ and $x$, is given by the salinity of the fluid entering the section at the inflow points minus the salinity of the fluid exiting the section at $X$ with flow rate $Q_{X}$ :

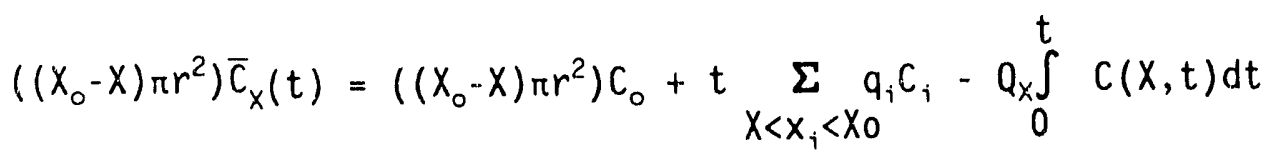

where $\left(X_{0}-X\right) \pi r^{2}$ is the wellbore volume in the section between $X_{0}$ and $X$, and $C(x, t)$ is the time-varying salinity at the location $x$. The first term on the right-hand side represents the background mean salinity in the wellbore.

If the electric conductivity $\sigma$ is linearly related to salinity, we can arrive at the following result by simple algebraic manipulations:

$$
Q_{x}=\frac{\underset{x<x_{i}<x_{0}}{\operatorname{at~} \sum q_{i} c_{i}-\left(\left(x_{0}-x\right) \pi r^{2}\right)\left[\sigma_{x}(t)-\sigma_{0}\right]}}{\int_{0}^{t}\left(\sigma(x, t)-\sigma_{0}\right) d t}
$$

where $\sigma_{x}(t)=\alpha \bar{C}_{x}(t)$ and $\sigma(x, t)=a C(x, t)$. Within the uncertainties caused by the approximations previously made, this equation gives the flow rate $Q_{x}$ at any location $X$ in the borehole directly without requiring a trial-arid-error procedure and is valid for any time $t$.

The first term in the numerator of equation (4-3) is given by equation (4-1), which can be applied to profiles at two successive times, $t_{2}$ and $t_{1}$, near each of the inflow points. We obtain 


$$
\alpha q_{i} c_{i}=\frac{\int_{x_{i}-\delta_{1}}^{x_{1}+\delta_{2}} \pi r^{2}\left(\sigma\left(x, t_{2}\right)-\sigma\left(x, t_{1}\right) d x\right.}{t_{2}-t_{1}}
$$

All the quantities in the right-hand side of equation (4-3) can be obtained from the measured electric conductivity profile.

Note that $\left(X_{0}-X\right) \pi r^{2}$ is an integral quantity representing the total borehole volume over the section $\left(x_{0}-x\right)$. Thus equation $(4-3)$ is not sensitive to local borehole radius variation, a major advantage over some of the conventional methods of measuring flow rates. Because of the integral forms of the terms in equations (4-3) and (4-4), the effects of solute dispersion around the peaks within the interval $x_{0}$ to $X$ do not influence the results. However, dispersion effects at or near $X$ introduce an error in the value of $c(x, t)$ or $\sigma(X, t)$. This is a major source of uncertainty in our parameter estimation. Examining the values of $Q_{x}$ determined from equation (4-3) at a series of locations between two successive peaks illustrates this uncertainty. At these locations, we know that $Q_{x}$ should be constant. The variation in $Q_{x}$ is a measure of solute dispersion in the borehole and can probably be studied to cancel $i$ ts effect and obtain the proper values of the flow raie. An alternative is $t c$ solve for $Q_{x}$ using equation (4-3) and then slightly adjust the value to match the field data by using a numerical fitting procedure, which is the approach used in this paper.

If $q_{i} C_{i}$ is constant for all inflow points, equation (4-3) holds for any time $t$. Thus solving the problem for a few different time periods should give the same result, which is a good internal check. This also means that short-term data may be sufficient to give accurate results. A reduction of the necessary measurement time (say, from 600 hours to 100 hours) represents a major saving in testing cost and makes the technology more commercially applicable.

\subsection{Transient Fracture Outflow}

If any $q_{i} C_{i}$ changes with time, $Q_{x}$ will also change with time. Thus applying equation (4-3) at different times will tell us (probably crudely) how $q_{i}$ changes with time. Note that if $C_{i}$ changes with time, but rot $q_{i}$, we expect that values of $Q_{x}$ obtained by equation $(4-3)$ will be the same for different times (so long as $t_{2}$ is set equal to $t$ and $t_{1}$ equal to zero in equation (4-4)). This means that the equation is appilicable even when $C_{i}$ from each inflow point varies with time!

in field operations, because of the fluid logging procedure or changing flow rates (transient effects), it is conceivable that flows from the fracturos into the wellbore do not initiate at the same time, but at $t_{i} ;$ thell an estimate for $t_{i}$ is obtained as follows: 


$$
t_{i}=t_{1}-\frac{\int_{x_{1}-\delta_{1}}^{x_{1}+\delta_{2}} \pi r^{2}\left(\sigma\left(x, t_{1}\right)-\sigma_{0}\right) d x}{\alpha a_{1} c_{1}}
$$

Equation (4-3) can also be easily modified to take this into account:

$$
\frac{\alpha \underset{x<x_{i}<x_{0}}{\Sigma}\left(t-t_{i}\right) q_{i} H\left(t-t_{i}\right)-\left(\left(x_{0}-x\right) \pi r^{2}\right)\left[\sigma_{y_{i}}(t)-\sigma_{0}\right]}{\int_{0}^{t}\left(\sigma(x, t)-\sigma_{0} d t\right.}
$$

where $H\left(t-t_{i}\right)$ is the Heaviside step function, which is 1 for $t>_{i}$ and 0 for $t s t_{i}$.

Here $\left(t-t_{i}\right) a_{i} c_{i}$ represents the total salinity input into the borehole from the fracture at $x_{i}$ during the time $\left(t-t_{i}\right)$. If the conductivity $\log$ is measured at time $t$ after the borehole is first flushed with de-ionized water, we can set $t_{1}=0$ and $t_{2}=t$ in equation (4-4); the total salinity input into the borehole is then given by

$$
\int_{a}^{1} \quad \int_{x_{1}-\delta_{1}}^{x_{1}+\delta_{2}} \pi r^{2}\left(\sigma(x, t)-\sigma_{0}\right) d x
$$

regardless of the values of $t_{i}$ and also regardless whether $a_{i}$ or $c_{i}$ is time dependent. Equation (4-6) can now be generalized to

$$
a_{x}=\frac{\underset{x<x_{i}<x_{0}}{\boldsymbol{\Sigma}} \int_{x_{1}-\sigma_{1}}^{x_{1}+\delta_{2}} \pi r^{2}\left(\sigma(x, t)-\sigma_{0}\right) d x-\left(\left(x_{0}-x\right) \pi r^{2}\right)\left[\sigma_{x}(t)-\sigma_{0}\right]}{\int_{0}^{t}\left(\sigma(x, t)-\sigma_{0}\right) d t}
$$

Here $Q_{x}$ has to be interpreted as a type of mean flow rate over the time period 0 to $t$ at location $X$.

Equation (4-3) assumes that all solute is flowing up the wellbore advectively and thus does not apply to locations in the wellbore where the solute flux is mainly down the borehole by diffusion. This is not a major restriction because avoiding these locations does not prevent us from obtaining the flow profile in the wellbore. In principle, all that is necessary is to apply the equation to a point on the downstream side (up the borehole) of each inflow point. 
A special case is when $\left(X_{0}-X\right)$ is small and $X$ is below (or upstream of) the first inflow point. If we apply equation (4-3) in this case, we obtain the indeterminate result $Q_{x}=0 / 0$. This is not surprising, indicating the simple result that without input salinity in the section of interest it is not possible to determine the flow rate.

The formulas in this section have been programmed into a simple code, called PRE (see HALE and TSANG, 1989). So far we have only applied equations $(4-1)$ to $(4-5)$ to a field case presented below. We have plans to study the use of equations (4-7) and (4-8) for time-varying $q_{1}$ and $c_{i}$. 


\section{APPLICATION OF MOMENT METHODS TO SYNTHETIC TEST CASES}

\subsection{Test Case Description}

Keeping in mind the type of data from the Leuggern field case, two bounding situations were selected to generate synthetic test cases. The first situation refers to fracture outflows that are separated widely from each other and that interfere only at late times. The second case reflects fractures that are closely spaced and already interfere strongly at early times. Both situations consider a low background salinity $(73 \mu \mathrm{S} / \mathrm{cm})$, time invariant fracture outflows, and have been modelled using the 10 finite difference transport simulator BORE (HALE and TSANG, 1988). The input data to BORE are shown in Table 5-1 and correspond to the final "best-fit" parameters for selected fractures of the Leuggern field data. The corresponding logs are shown on Fig. 5-1 and 5-2. Also note, that case II includes the simulation of a zero concentration flow from below the deepest (saline) fracture outflow. The true Leuggern field data are analyzed in section 6.

\subsection{Application of the Classical Moment Method}

\section{SYNTHETIC TEST CASE I}

The mass rate $\left(q_{j} c_{i}\right)$ and the volumetric flow rates derived from the zero'th and the first moment of the individual peaks of test case I are shown in Table 5-2. The output parameters correspond to average values over the times when the individual peaks are not interfering (compare Fig. 5-1).

\begin{tabular}{|c|c|c|c|c|c|}
\hline DEPTH & \multicolumn{5}{|c|}{$\begin{array}{c}q_{i}, Q:\left[1 \mathrm{E}-6 \mathrm{~m}^{3} / \mathrm{s}\right], q_{i} C_{i}:[1 \mathrm{E}-6 \mathrm{~kg} / \mathrm{s}], t:[\mathrm{hr}] \\
\text { Output (MOMENT) }\end{array}$} \\
\hline $\begin{array}{l}849 \\
918 \\
1200 \\
1440\end{array}$ & $\begin{array}{l}80 \\
4.5 \\
3.7 \\
1.2\end{array}$ & $\begin{array}{l}68 \\
14.0 \\
2.5 \\
0.85\end{array}$ & $\begin{array}{l}67 \\
13.7 \\
2.5 \\
0.85\end{array}$ & $\begin{array}{l}69 \\
6.2 \\
3.7 \\
1.79\end{array}$ & $\begin{array}{l}3 \\
3-12 \\
3-96 \\
3-144\end{array}$ \\
\hline
\end{tabular}

Table 5-2: Comparison of Simulation Input and Classical Moment Output for Synthetic Test Case I $\left(q_{i}=\right.$ fracture flow rate, $q_{i} c_{i}=$ fracture mass rate, $t=$ logging time of logs used for the analysis)

Table 5-2 shows that the mass rates of the different fractures can be reproduced very accurately. The fracture fluxes can be estimated with an error of smaller than $50 \%$. The relatively large difference with respect to the outflow at $1440 \mathrm{~m}$ could be related to the influence of the lower modelling boundary which affects this peak at late times. 
These errors will translate to transmissivity errors of about the same size, implying that the method could be a useful approach also for field applications when peaks are not strongly interfering. Also note that from knowing $q_{1} c_{1}$ and $q_{1}$ the fracture fluid concentration can easily be determined.

\begin{tabular}{|c|c|c|}
\hline & TEST CASE I & TEST CASE II \\
\hline $\begin{array}{l}\text { BOREHOLE PARAMETERS } \\
\text { Cell Length }[\mathrm{m}] \\
\text { Diameter }[\mathrm{cm}] \\
\text { Dispersion }\left[\mathrm{m}^{2} / \mathrm{s}\right]\end{array}$ & $\begin{array}{l}1 \text { or } 5 \\
14 \\
0.5 E-3\end{array}$ & $\begin{array}{l}0.25 \text { or } 1 \\
14 \\
1.05-3\end{array}$ \\
\hline $\begin{array}{l}\text { FRACTURE PARAMETERS } \\
\text { POSition [m b.g.] } \\
\text { Flux }\left[\mathrm{m}^{3} / \mathrm{s}\right] \\
\text { Concentration }\left[\mathrm{kg} / \mathrm{m}^{3}\right]\end{array}$ & $\begin{array}{l}1440 \\
1.2 \mathrm{E}-6 \\
0.71\end{array}$ & $\begin{array}{l}1299 \\
1.57 E-6 \\
0.0\end{array}$ \\
\hline $\begin{array}{l}\text { FRACTURE PARAMETERS } \\
\text { POsition [m b.g.] } \\
\text { Flux }\left[\mathrm{m}^{3} / \mathrm{s}\right] \\
\text { Concentration }\left[\mathrm{kg} / \mathrm{m}^{3}\right]\end{array}$ & $\begin{array}{l}1200 \\
3.7 \mathrm{E}-6 \\
0.68\end{array}$ & $\begin{array}{l}1270 \\
1.5 e-7 \\
0.55\end{array}$ \\
\hline $\begin{array}{l}\text { FRACTURE PARAMETERS } \\
\text { Position [m b.g.] } \\
\left.\text { Concentration i } \mathrm{kg} / \mathrm{m}^{3}\right] \\
\text { Flux }\left[\mathrm{m}^{3} / \mathrm{s}\right]\end{array}$ & $\begin{array}{l}918 \\
3.10 \\
4.5 \mathrm{E}-6\end{array}$ & $\begin{array}{l}1248 \\
0.541 \\
6.0 E-7\end{array}$ \\
\hline $\begin{array}{l}\text { FRACTURE PARAMETERS } \\
\text { POSition [m b.g.] } \\
\text { Flux }\left[\mathrm{m}^{3} / \mathrm{s}\right] \\
\text { Concentration }\left[\mathrm{kg} / \mathrm{m}^{3}\right]\end{array}$ & $\begin{array}{l}849 \\
8.0 \mathrm{E}-5 \\
0.85\end{array}$ & $\begin{array}{l}1215 \\
1.0 \mathrm{E}-6 \\
0.60\end{array}$ \\
\hline $\begin{array}{l}\text { FRACTURE PARAMETERS } \\
\text { POsition }[\mathrm{m} \mathrm{b} \cdot \mathrm{g} \cdot] \\
\text { Flux }\left[\mathrm{m}^{3} / \mathrm{s}\right] \\
\text { Concentration }\left[\mathrm{kg} / \mathrm{m}^{3}\right]\end{array}$ & & $\begin{array}{l}1201 \\
2.7 \mathrm{E}-6 \\
0.65\end{array}$ \\
\hline $\begin{array}{l}\text { FRACTURE PARAMETERS } \\
\text { POsition }[\mathrm{m} \mathrm{b} . \mathrm{g} .] \\
\text { Flux }\left[\mathrm{m}^{3} / \mathrm{s}\right] \\
\text { Concentration }\left[\mathrm{kg} / \mathrm{m}^{3}\right]\end{array}$ & & $\begin{array}{l}1188 \\
1.0 \mathrm{E}-6 \\
0.595\end{array}$ \\
\hline $\begin{array}{l}\text { TIME PARAMETERS } \\
\text { Time Step [min] } \\
\text { Log Times [hr] }\end{array}$ & $\begin{array}{l}15 \\
0.5,3,5,8,12, \\
16,24,48,96, \\
144,288,600 \\
(192,384,480)\end{array}$ & $\begin{array}{l}15, \\
0.5,3,5,8,12, \\
16,24,48,96, \\
144,192,288, \\
384,480,600\end{array}$ \\
\hline
\end{tabular}




\section{SYNTHETIC TEST CASE II}

The mass rates $\left(q_{1} c_{i}\right)$ derived from the zero'th moment of the individual peaks of test case II are shown in Table 5-3. The rates correspond to average values over the times when the individual peaks are not, or only slightly, interfering (compare Fig. 5-2).

\begin{tabular}{|c|c|c|c|c|c|}
\hline DEPTH & \multicolumn{5}{|c|}{$\begin{array}{cc}q_{i}, Q:\left[1 \mathrm{E}-6 \mathrm{~m}^{3} / \mathrm{s}\right], & q_{i} C_{i}:[1 \mathrm{E}-6 \mathrm{~kg} / \mathrm{s}], t:[\mathrm{hr}] \\
\text { Input (BORE) } & \text { Output (MOMENT) }\end{array}$} \\
\hline $\begin{array}{l}1188 \\
1201 \\
1215 \\
1248 \\
1270 \\
1299\end{array}$ & $\begin{array}{l}1.0 \\
2.7 \\
1.0 \\
0.6 \\
0.15 \\
1.57\end{array}$ & $\begin{array}{l}0.60 \\
1.76 \\
0.60 \\
0.32 \\
0.08 \\
0.00\end{array}$ & $\begin{array}{l}0.71 \\
1.65 \\
0.57 \\
0.33 \\
0.08 \\
-\end{array}$ & $\begin{array}{l}- \\
- \\
- \\
- \\
- \\
-\end{array}$ & $\begin{array}{l}0-0.5 \\
0-0.5 \\
0-0.5 \\
0-5 \\
0-5 \\
-\end{array}$ \\
\hline
\end{tabular}

Table 5-3: Comparison of Simulation Input and Classical Moment Output for Synthetic Test Case II ( $q_{i}$ fracture flow rate, $q_{i} C_{i}=$ fracture mass rate, $t=$ logging time of logs used for the analysis)

Table 5-3 shows that, as in the first test case, the mass rates of the different fractures rai be reproduced very accurately. The high accuracy of the derived mass rates results in this case from the fact that the rates have been calculated by including an ideal time zero data point (with a zero moment value of $\cup .0$ ) in the analysis. The fracture fluxes can not be determined from the classical moment quantities, because time derivatives of the first moment cannot be calculated (not enough points in time) and the zero concentration outflow at $1299 \mathrm{~m}$ is not analyzable by this method. However, the volumetric fracture outflows could still be estimated if the fracture fluid concentration where known (e.g. from water sampling).

\subsection{Application of the Partial Moment Method}

\section{SYNTHETIC TEST CASE I}

A plot of the zero Partial Moment versus time for a series of intervals between the fracture outflows defined on Table 5-1 is shown on Figure 5-3. For the cases considered, the zero'th and first Partial Moment plots are qualitatively identical, because the integration distance 1 is always very small compared to the depth value $x$. Therefore a qualitative discussion of both Partial Moments can be limited to Fig. 5-3.

The positions of the integration boundaries were selected such that the resulting integration intervals were as large as possible. Slopes at the integration boundaries were calculated by 1 inear least squares fitting through 5 or 7 points around the boundary (measurements every 
$1 \mathrm{~m})$. The time derivatives of the Partial Moments were calculated from linear least square fits through 3 points in time.

Based on the criteria listed in section 3.3 one can conclude from Figure 5-3, that interval 1205-1435 $\mathrm{m}$ should yield relatively precise and stable results for all logging times. The opposite can be expected for interval $710-845 \mathrm{~m}$, where the only reliable wellbore velocity values can be expected for 3 and 5 hrs after start of flow (the other times show either small temporal changes in the partial moments or strong "kinks" due to peak interference effects). For interval 923$1195 \mathrm{~m}$, the first $96 \mathrm{hrs}$ and for interval 923-1195 m the first $10 \mathrm{hrs}$ should be weighted high when estimating the proper wellbore velocities. For these two intervals all calculated velocities as a function of time are plotted in Figure 5-4 as sample cases.

Selecting and averaging the appropriate interval velocities results in the values listed in Table 5-4. The individual fracture fluxes $q_{1}$ can easily be calculated from the backward (downstream) differences of the wellbore fluxes Q.

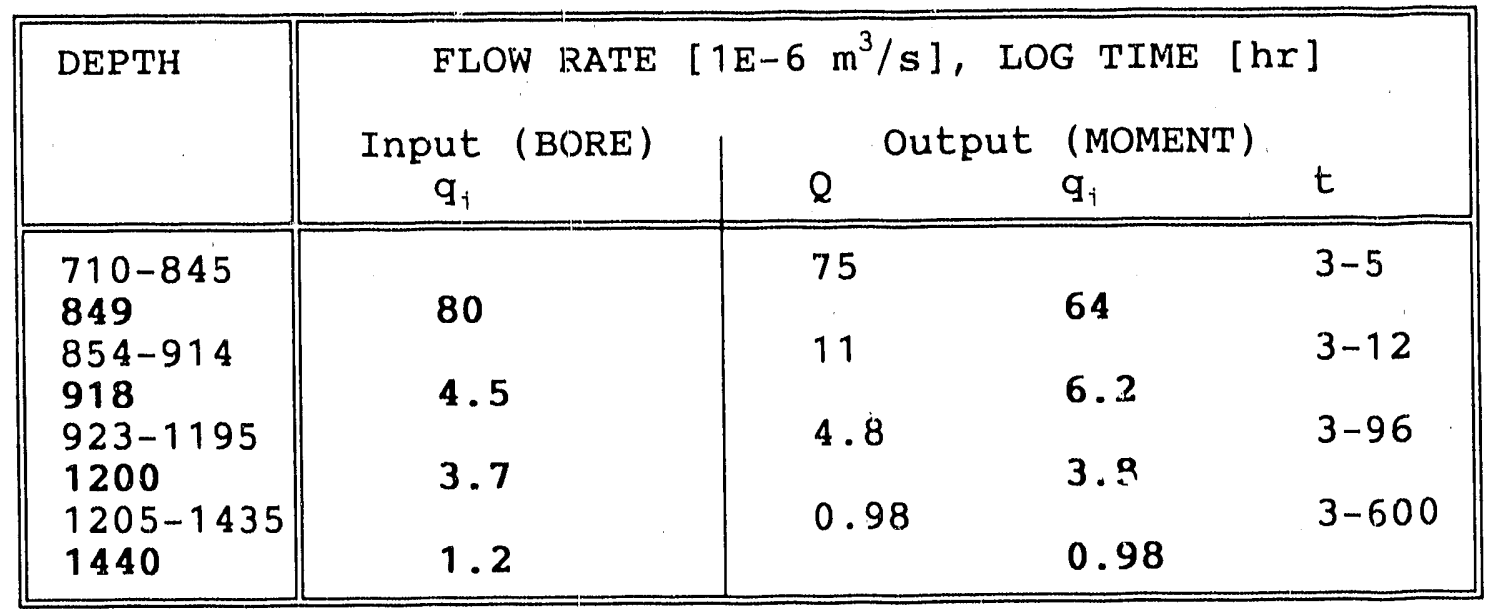

Table 5-4: Comparison of Simulation Input and Partial Moment Output for Synthetic Test Case I $\left(q_{i}=\right.$ fracture flow rate, $Q=$ wellbore flow rate in between fractures, $t=$ logging time of logs used for the analysis)

Table 5-4 shows that the flow rates of the test case 1 can be reproduced within an error of less than 50\%. As expected, intervals 3 and 4 show the best results with an error of about $10 \%$.

\section{SYNTHETIC TEST CASE II}

A plot of the zero Partial Moment versus time for the intervals between the fracture outflows of case II (see Table 5-1) is shown in Fig. 5-5. The same criteria were used for the selection of integration boundaries as in the first case. Measurement points were available in $0.25 \mathrm{~m}$ steps. 
Figure 5-5 implies that for the generally more difficult case II strongly interfering peaks - we can expect even better results than for the synthetic test case I. Up to relatively late times (around 100 hrs), the zero'th Partial Moments of all intervals smoothly increase in time at a relatively high rate. The weighted fracture outflow rates are presented in Table 5-5. The time intervals selected for Table 5-5 correspond to those, where the $I_{0 t}$ values are relatively big and the wellbore velocities form stable plateaus on velocity versus time plots.

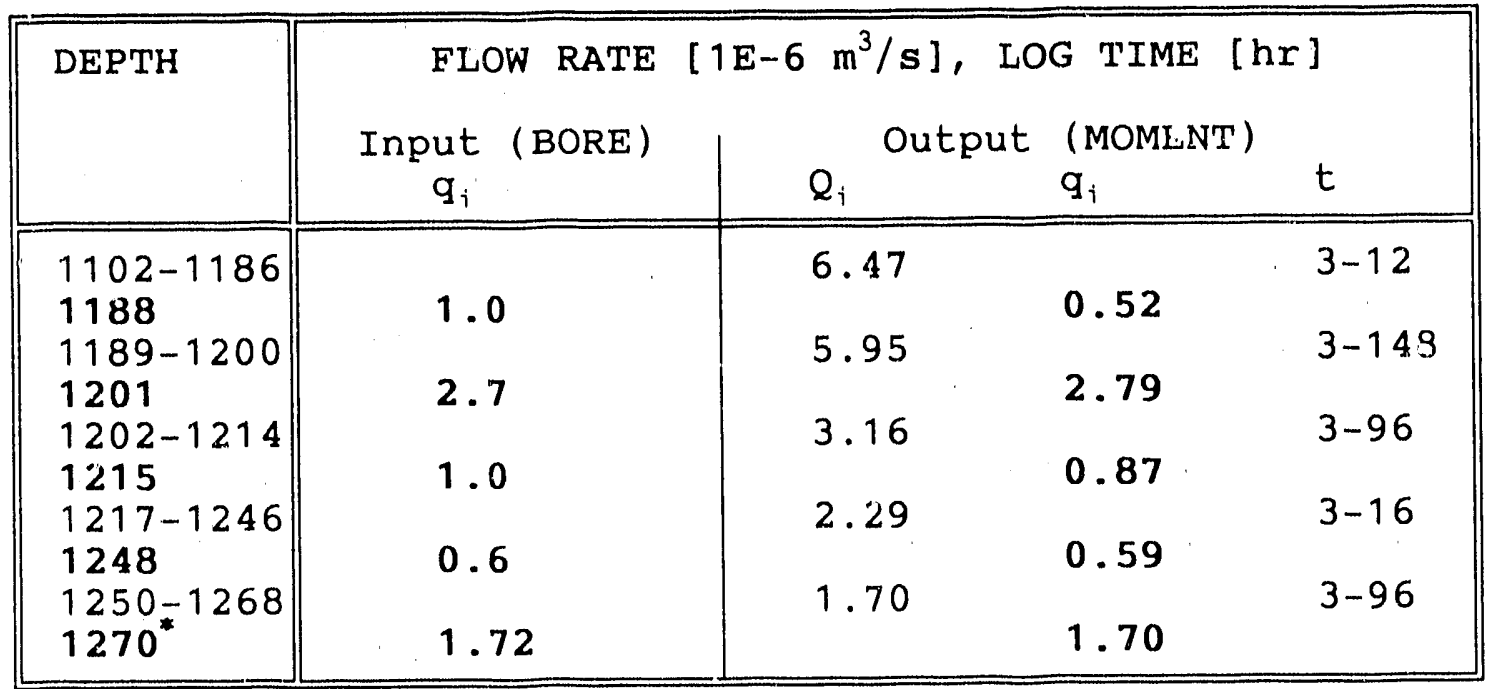

Table 5-5: Comparison of Simulation Input and Partial Moment Output for Synthetic Test Case II $\left(Q_{i}=\right.$ fracture flow rate, $Q_{i}=$ wellibore flow rate in between fractures, $t=$ logging time of logs used for the analysis). The outflow marked "1270*" covers both fractures at 1270 and $12.99 \mathrm{~m}$.

For interval 1272-1297 the $I_{\text {ot }}$ values are small for all times, implying a great sensitivity to calculation errors. This is evident from the observation that including 5 or 7 measurements points in the calculation of the $C_{x A}$ and $C_{x B}$ values strongly affects the calculated fluxes. For this reason no values for this interval have been given and the wellbore flux calculated for interval 5 (1250-1268 $\mathrm{m}$ ) corresponds to the summed fracture outflows at 1277 and $1299 \mathrm{~m}$.

Tables 5-4 and 5-5 show the clear tendency that the higher up the fractures are located the larger are the errors. This stems from the simple fact that the wellbore velocity increases uphole and, therefore, the relative error of this parameter becomes a bigger value in this direction. This implies that for homogeneous fracture flow distribution along the logging section (i.e. similar fluxes for all fractures), small fractures located higher up in the hole become less well determined. 


\subsection{Application of the Direct Integral Method}

\section{SYNTHETIC TEST CASE I}

The results from the PRE approach are shown in Table 5-6. In these calculations, as well as those for synthetic test case II, we have adopted the convention that $Q_{x}$ is calculated on the downstream side and very close to each fluid conductivity peak (see equation 4-3 in section 4). Thus the flow fram each peak, $q_{i}$ is the difference between $Q_{x}$ value at this peak and the value near the previous upstream peak. The results compare well with the BORE input used to generate the synthetic data. The maximum error in the analysis is $30 \%$ (deepest inflow peak).

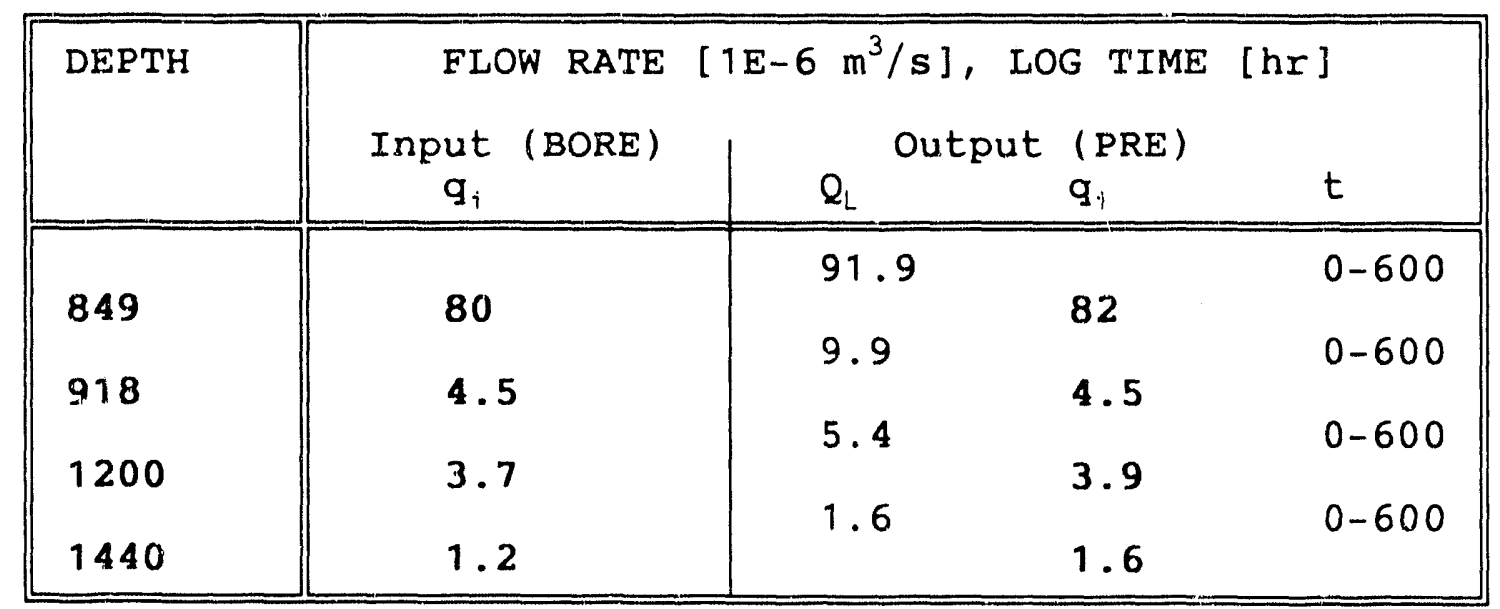

Table 5-6: Comparison of Simulation Input and PRE Output for Synthetic Test Case I $\left(Q_{i}=\right.$ fracture flow rate, $Q_{L}=$ we 71 bore flow rate in between fractures, $t=$ logging time of logs used for the analysis)

\section{SYNTHETIC TEST CASE II}

In this case the results from PRE, shown in Table 5-7, still compare quite well with the BORE input used to generate the synthetic data. The greatest difference $(40 \%)$ is found in the first, or most downstream, peak. This might again be explained by the increase of the relative wellbore velocity (or flux) error value in the downstream direction. Like the methods discussed in sections 5.2 and 5.3, the Direct Integral Approach has difficuities quantifying the zero-concentration outflow at $1299 \mathrm{~m}$. Therefore again, only the fluxes above $1277 \mathrm{~m}$ are compared. 


\begin{tabular}{|c|c|c|c|c|}
\hline DEPTH & $\begin{array}{l}\text { FLOW RATE } \\
\text { Input (BORE) } \\
q_{i}\end{array}$ & $\begin{array}{c}\left.6 \mathrm{~m}^{3} / \mathrm{s}\right] \\
Q_{L} \\
\end{array}$ & $\begin{array}{l}\text { G TIME } \\
(\mathrm{PRE}) \\
\mathrm{q}_{i} \\
\end{array}$ & $t$ \\
\hline $\begin{array}{c}1188 \\
1201 \\
1215 \\
1248 \\
1270^{*}\end{array}$ & $\begin{array}{l}1.0 \\
2.7 \\
1.0 \\
0.6 \\
1.72\end{array}$ & $\begin{array}{l}6.47 \\
5.95 \\
3.16 \\
2.29 \\
1.70\end{array}$ & $\begin{array}{l}1.4 \\
2.6 \\
0.51 \\
0.93 \\
1.8 \\
\end{array}$ & $\begin{array}{l}0-600 \\
0-600 \\
0-600 \\
0-600 \\
0-600\end{array}$ \\
\hline
\end{tabular}

Table 5-7: Comparison of Simulation Input and PRE Output for Synthetic Test Case II $\left(q_{i}=\right.$ fracture flow rate, $Q_{L}=$ wellbore flow rate in between fractures, $t=$ logging time of logs used for the analysis). The outflow marked "1270*" covers both fractures at 1270 and $1299 \mathrm{~m}$. 


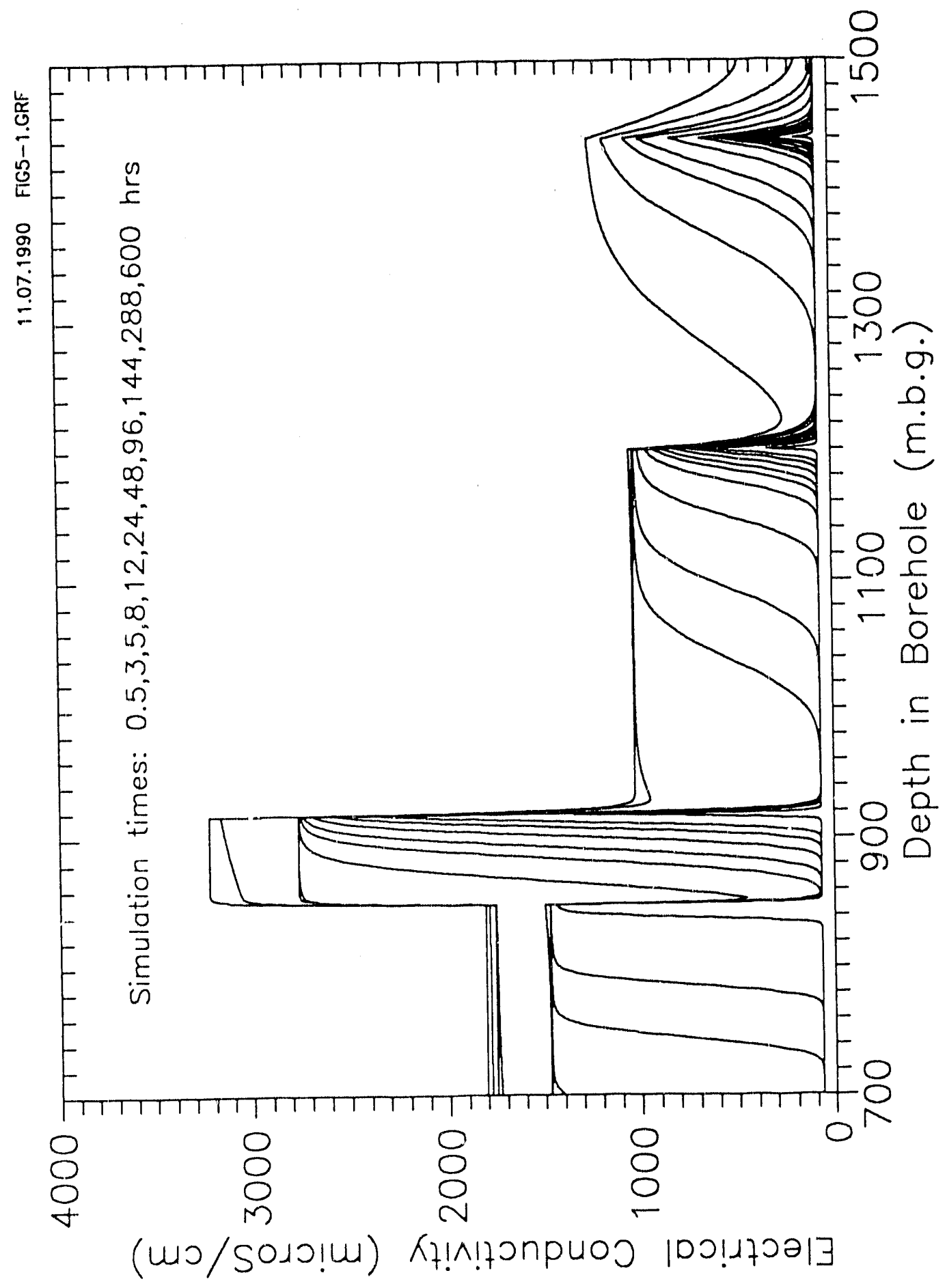

Fig. 5-1: Fluid electrical conductivity logs for synthetic test case I 


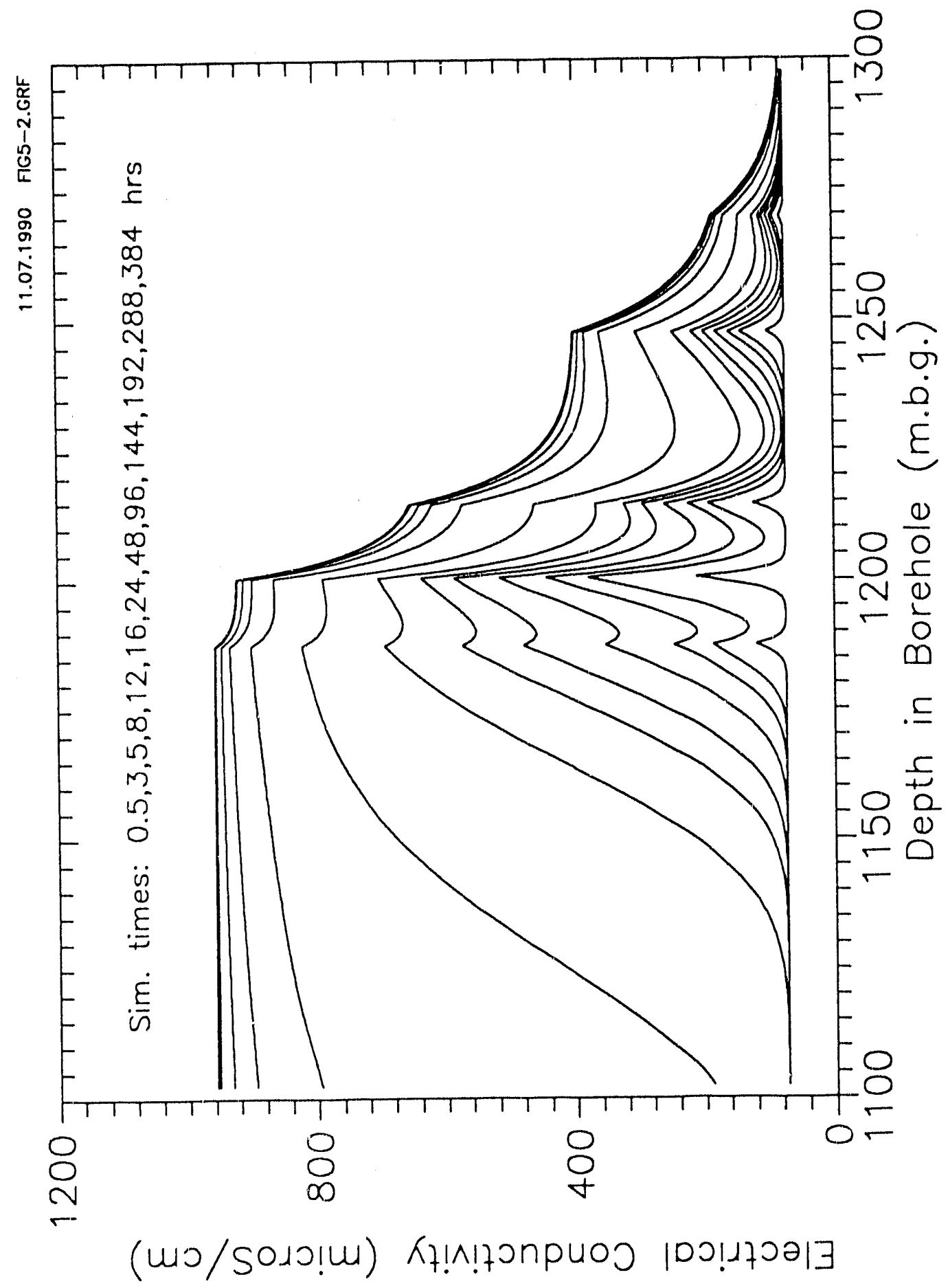

Fig. 5-2: Fiuid electirical conductivity logs for synthetic test case II 


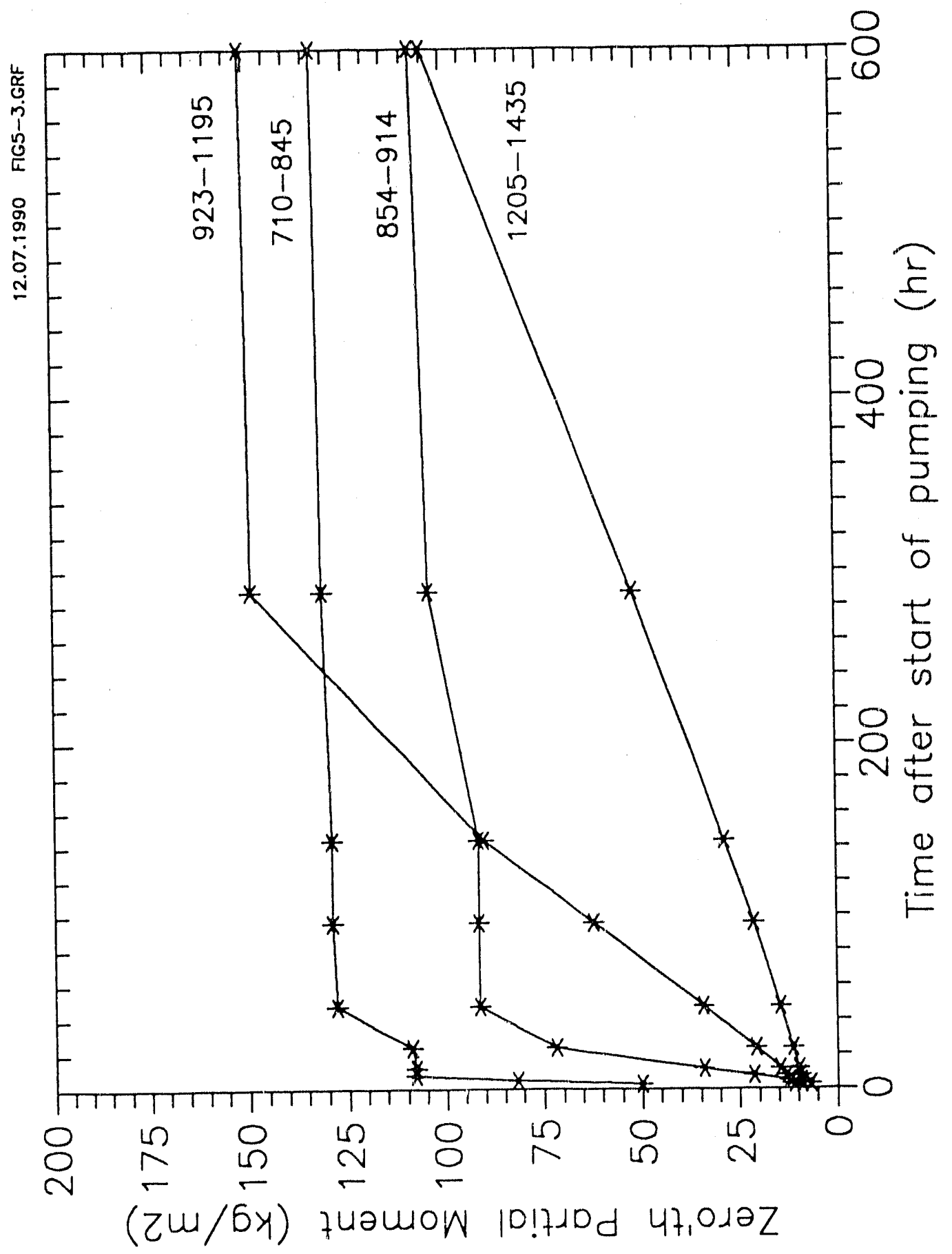

Fig. 5-3: Zero Partial Moment versus time for synthetic test case II (integration intervals are indicated) 


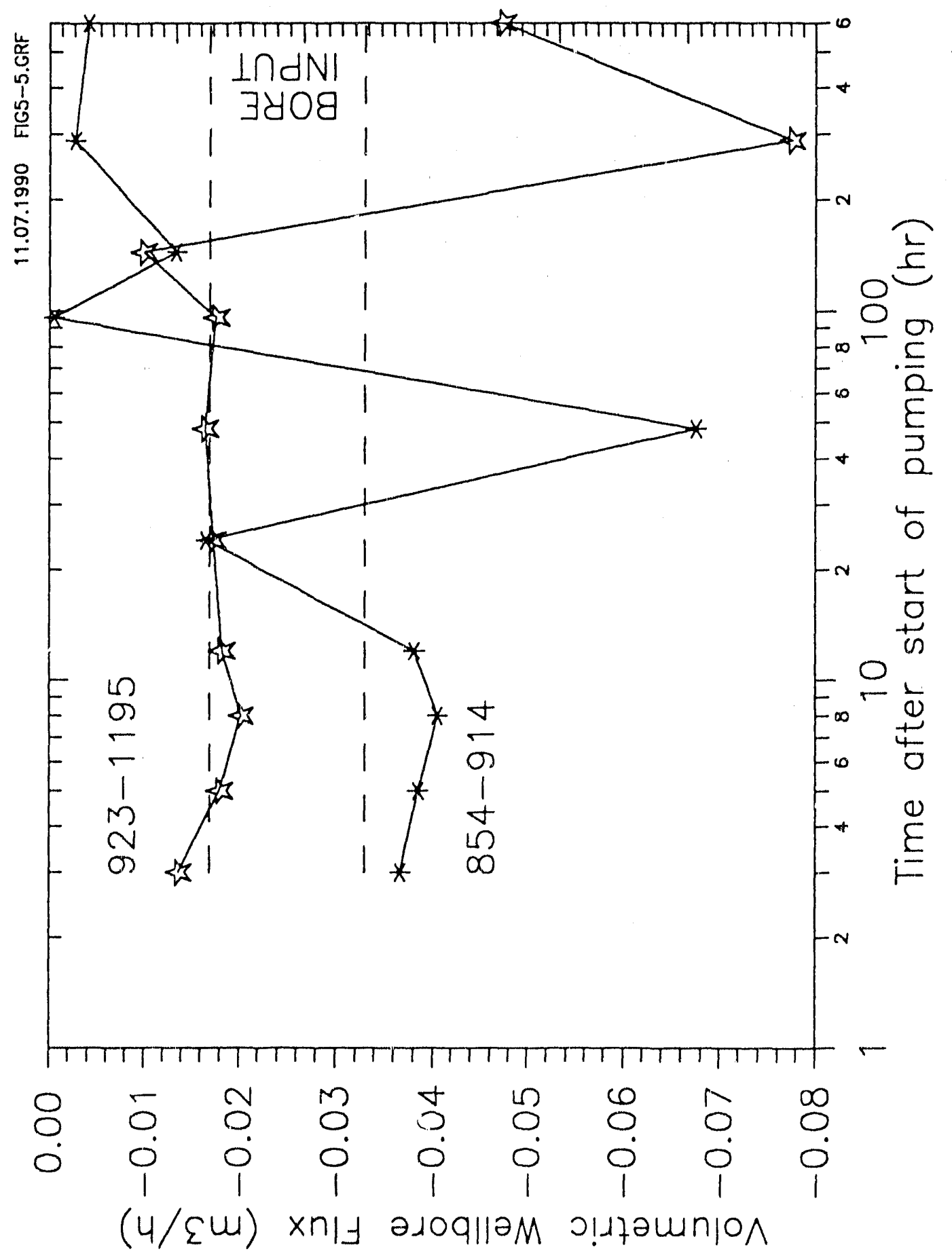

Fig. 5-4: Volumetric wellbore-flow rates as a function of time, examples cases from 2 intervals of synthetic test case 1 , and comparison with BORE input velocities 


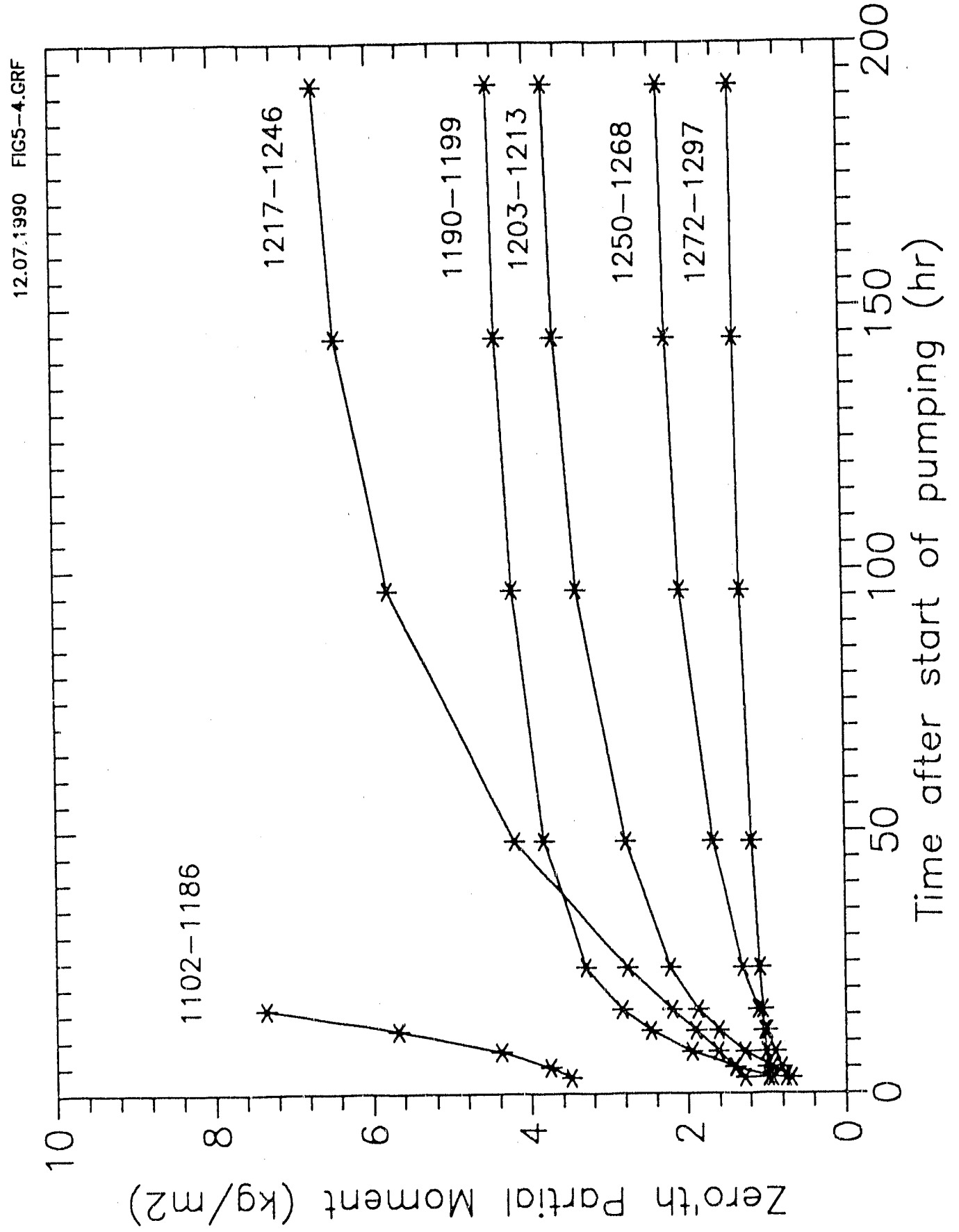

Fig. 5-5: Zero Partial Moment versus time for synthetic test case II (integration intervals are indicated) 


\section{6 \\ APPLICATION OF MOMENT METHODS TO FIELD DATA}

\subsection{Description of Leuggern 1987 Fluid Logging and Data Conversion}

The fluid logging technique has been applied to the Leuggern deep well in Northern Switzerland. Drilling of the borehole began in June 1984 and was completed in February 1985 to a total depth of $1,688.9 \mathrm{~m}$. The borehole deviated from vertical and thus, the true depth below ground surface is $1,631.6 \mathrm{~m}$. In this paper, depth is measured along the borehole. The geology and borehole characteristics of the Leuggern borehole are presented in Fig. 6-1. A detailed description of the Leuggern deep well can be found in NAGRA (1990).

The section of the borehole from 700 to $1,600 \mathrm{~m}$ was logged for fluid conductivity. This zone is fractured crystalline rock, mainly biotite gneiss and granite. The diameter of the zone of interest lies between $0.14 \mathrm{~m}$ and $0.16 \mathrm{~m}$.

Fluid conductivity logging has been applied twice over large sections of the Leuggern borehole, in 1985 and in 1987. The 1985 measurements were analyzed by TSANG et al. (1990). In 1987 additional, more detailed, fluid conductivity logging measurements were taken and described in detail in VERSTRAETE (1988).

Two sets of fluid conductivity logging measurements were taken in 1987 in Leuggern. The first set of 17 runs (Fig. 6-2) lasted about 600 hours after start of pumping and is used in the present report to demonstrate the applicability of the various moment-related analysis methods. A constant pumping rate of $24 \mathrm{l} / \mathrm{min}$ was established after approximately 5 hours, which included substantial fracture outflow from above the logged section. In the 1987 conductivity logs, 13 major inflow points were evident in the logged section.

A study reiated to the conversion of measured electrical conductivities to electrolyte concentrations is presented in TSANG et al. (1990). For an $\mathrm{NaCl}$ solution at $20^{\circ} \mathrm{C}$, a least squares fit between these two parameters yields the following quadratic approximation:

$$
\sigma=1,870 C-45 C^{2}
$$

where $C$ is the concentration in $\mathrm{kg} / \mathrm{m}^{3}$ and $\sigma$ is the conductivity in $\mu \mathrm{s} / \mathrm{cm}$. The expression is accurate for a range of $C$ up to $5 \mathrm{~kg} / \mathrm{m}^{3}$, (o up to $10,000 \mu \mathrm{s} / \mathrm{cm}$ ). For lower $C$ up to $1 \mathrm{~kg} / \mathrm{m}^{3}$ (o up to $2,000 \mu \mathrm{s} / \mathrm{cm}$ ), the second term can be negiected.

For solutes other than $\mathrm{NaCl}$, equivalent $\mathrm{NaCl}$ concentrations can be calculated (SCHLUMBERGER, 1984). The main components of the sampled formation waters in the crystalline rocks of Leuggern are $\mathrm{Na}^{+}(80-90 \%$ of total cations $), \mathrm{SO}_{4}{ }^{2-}(40-80 \%$ of total anions $), \mathrm{HCO}_{3}(10-30 \%$ of total anions) and $\mathrm{Cl}^{-}(7-60 \%$ of total anions). The equivalent $\mathrm{NaCl}$ solutions with respect to electrical resistivity for this range of chemistry lie within about 60 to $90 \%$ of the pure $\mathrm{NaCl}$ solutions. Therefo$r e$, the approximation described above, correlating electrical conductivity and electrolyte concentration, leads to a slight underestimation of the concentration. However, when compared to other uncertainties in 
the analysis (see Section 5), this deviation can be neglected.

The temperature data recorded were used to correct for temperature dependence of the conductivity measurements. The reference temperature used is $20^{\circ} \mathrm{C}$. The conductivity reduction to $20^{\circ} \mathrm{C}$ for other temperatures was determined experimentally (see VERSTRAETE, 1988).

These 1987 data were analyzed by LOEW et al. (1989) with direct and iterative methods, including a detailed best-fit analysis with BORE. The transmissivities derived from these results were compared with results from packer tests performed extensively in the Leuggern borehole (BELANGER et al. 1989). It is shown that the packer test results are reproduced by fluid logging experiments within the measurement limits of packer testing. In addition, the solute concentration results from water sampling could be matched relatively well.

In section 6.2 the back-calculated fracture fluxes from packer test results are used as reference vaiues for the comparison with the results from the moment-related methods presented in sections 3 and 4 of this report. In case of multiple packer tests straddling the same fracture outflows, the packer test with the longest duration has been selected fur comparison. Also, the products of fracture fluid concentration (from water sampling) and fracture volumetric flux from packer testing is used for comparison with the classical zero moment results. 


\subsection{Application of Moment Methods to the Leuggern 1987 Data}

\section{CLASSICAL MOMENT METHOD}

The mass fluxes released by the individual fractures and calculated from the zero moments are compared to the packer test results in Table 6-1. The fracture flow rates, $q_{1}$ were calcuiated for $t=10 \mathrm{hrs}$ and assuming a storativity of $2.2 E-06$. The fracture fiuid concentrations were calculated from the water sample chemistry, normalized to $20^{\circ} \mathrm{C}$.

\begin{tabular}{|c|c|c|}
\hline $\begin{array}{c}\text { Depth } \\
(\mathrm{m})\end{array}$ & \multicolumn{2}{|c|}{$[1 \mathrm{E}-6 \mathrm{~kg} / \mathrm{s}]$} \\
& Packer T. & MOMENT \\
& $\mathrm{q}_{\mathrm{i}} \mathrm{C}_{\mathrm{f}}$ & $\mathrm{q}_{+} \mathrm{C}_{\mathrm{i}}$ \\
\hline \hline 843. & 78.0 & 21.00 \\
920. & 6.9 & 7.5 \\
1047. & $\mathrm{n} . \mathrm{d}$. & 0.55 \\
1083. & $\mathrm{n} . \mathrm{d}$. & 0.25 \\
1188. & $\mathrm{n} . \mathrm{d}$. & 0.8 \\
1201. & $\mathrm{~s}: \mathrm{0.97}$ & 1.5 \\
1215. & $\mathrm{n} . \mathrm{d}$. & 0.7 \\
1248. & $\mathrm{n} . \mathrm{d}$. & 0.5 \\
1270. & $\mathrm{n} . \mathrm{d}$. & 0.09 \\
1300. & $\mathrm{n} . \mathrm{d}$. & 0.25 \\
1325. & n.d. & 0.7 \\
1440. & 0.44 & 0.72 \\
\hline
\end{tabular}

Table 6-1: Comparison of Mass Rates derived from Packer Testing/Sampling and Zero Moment Results. The Mass Flux indicated as "S: 0.97 " corresponds to the summed Fluxes of the Fractures at 1188,1201 , and $1215 \mathrm{~m}$. "n.d." refers to fractures where no fluid chemistry data (water samples) are available.

Table 6-1 shows that the mass rates derived by the two methods correspond within half-orders of magnitude, but are not in truly close agreement when all intervals are considered together. The reason for this deviation is unclear at the moment and may be related to both of the methods considered.

Because the peaks interfere at very early times, a detailed first moment analysis was not conducted. If one assumes a constant fracture fluid electrolyte concentration of $1 \mathrm{~kg} / \mathrm{m}^{3}$ the Moment estimated fluxes are already fairly good estimations compared to the packer test derived values displayed in Table 6-2.

\section{PARTIAL MOMENT METHOD}

A plot of the zero'th Partial Moments versus time for sciected intervals between the fracture outflows shown in Fig. 6-2 is presented in Fig. 6-3. Based on this figure it can be asslimed that the Partial 
Moment Method should be applicable to early time data of this experiment. For the weighting of the different wellbore fluxes the criteria presented in section 3.3 have been used. The threshold value of the time derivative of the zero'th Partial Moment used corresponds to $5 \mathrm{E}-$ $02 \mathrm{~kg} / \mathrm{m}^{2} \star \mathrm{h}$. Table 6-2 summarizes the results and compares them to the packer test derived parameters $(S=2.2 E-6, t=10 \mathrm{hr})$.

\begin{tabular}{|c|c|c|c|c|c|}
\hline \multirow{3}{*}{$\begin{array}{c}\text { Depth } \\
\text { (m) }\end{array}$} & \multicolumn{5}{|c|}{ FLOW RATE [1E-6 $\mathrm{m} 3 / \mathrm{s}]$, LOG TIME [hr] } \\
\hline & \multirow{2}{*}{$\begin{array}{c}\text { Packer } \mathrm{T} . \\
\mathrm{q}_{\mathrm{i}} \\
\end{array}$} & \multicolumn{4}{|c|}{ MOMENT } \\
\hline & & Q & $q_{1}$ & $q_{i}^{\prime}$ & $t$ \\
\hline & & 45.2 & & & $3-8$ \\
\hline & 102 . & & 30.4 & 30.4 & $3-284$ \\
\hline 920. & 2.62 & 7.14 & 7.66 & 7.66 & $3-24$ \\
\hline 1047 & 0.10 & 7.00 & 0.14 & 0.14 & $3-5,48-144$ \\
\hline 1083 & 0.27 & 5.56 & 1.44 & 1.44 & $3-144$ \\
\hline 1188 & $\mathrm{~S} 1: 1.0$ & 0.0 & & 0.95 & \\
\hline 1201 & $\mathrm{~S} 2: 1.4$ & 4 & S2: 2.8 & 0.95 & \\
\hline 1215 & 0.44 & 2.72 & & 0.95 & $3-24$ \\
\hline & 0.27 & 1.80 & 0.92 & 0.92 & $3-48$ \\
\hline & 0.24 & 0.73 & 1.07 & 1.07 & $3-48$ \\
\hline $\begin{array}{l}1325 \\
1440\end{array}$ & $\begin{array}{l}0.08 \\
0.41\end{array}$ & 0.68 & $\begin{array}{l}0.05 \\
0.68\end{array}$ & $\begin{array}{l}0.05 \\
0.68\end{array}$ & $5-480$ \\
\hline
\end{tabular}

Table 6-2: Comparison of packer test and Partial Moment results for the Leuggern field data $\left(q_{i}=\right.$ primary fracture flow rate, $q_{i}{ }^{\prime}=$ adjusted fracture flow rate, $Q=$ well lbore flow rate in between fractures, $t=10 \mathrm{gging}$ time of logs used for the analysis, n.d. = not determined). The flux marked as "S2" corresponds to the summed fracture outflows for the fractures located at 1188,1202 and $1215 \mathrm{~m}$. The value marked with "S1" covers both outflows at 1188 and $1201 \mathrm{~m}$. 
The intervals between the fractures located at 1188, 1201 and 1215 are too small for Partial Moment analysis (results are very unstable). Therefore the total fracture outflow of the entire section was equaliy distributed over the individual fractures. As an internal check of the data, one can assume that the wellbore velocity should monotonically increase from the bottom to the top of the logged section, because the drawdown in the borehole during this test $(245 \mathrm{~m})$ was large compared to the head differences of the individual fractures considered (BELANGER et a1. 1989). This is indeed the case for the data shown in Table 6-2.

The difference between the fluid logging and the packer testing method is in general within a factor of 2 or 3 with the greatest differences being smaller than half an order of magnitude. Taking into account the variations of derived $q$ or $T$ from packer testing alone (different packer tests straddling the same intervals show differences in $T$ of up to 1 order of magnitude and more, see BELANGER et a1. 1989), these results must be considered as very favourable.

Comparing the Moment derived fluxes with the BORE derived values presented in TSANG et a1. (1990), it can be observed that the greatest deviations are found for the peaks at 920,1047 and $1325 \mathrm{~m}$. These are, however, fractures where the packer test results are in close agreement with the results from the Partial Moment method, suggesting that for certain cases the Partial Moment method might directly give even better results than a fitting procedure using BORE. 


\section{DIRECT INTEGRAL METHOD}

In applying PRE or moment methods directly to field data inaccuracies in the data can play a significant role. When we apply PRE to the actual logs (up to 96 hours) from the first phase of the 1987 experiment we obtain the results shown in the Q-column of Table 6-3.

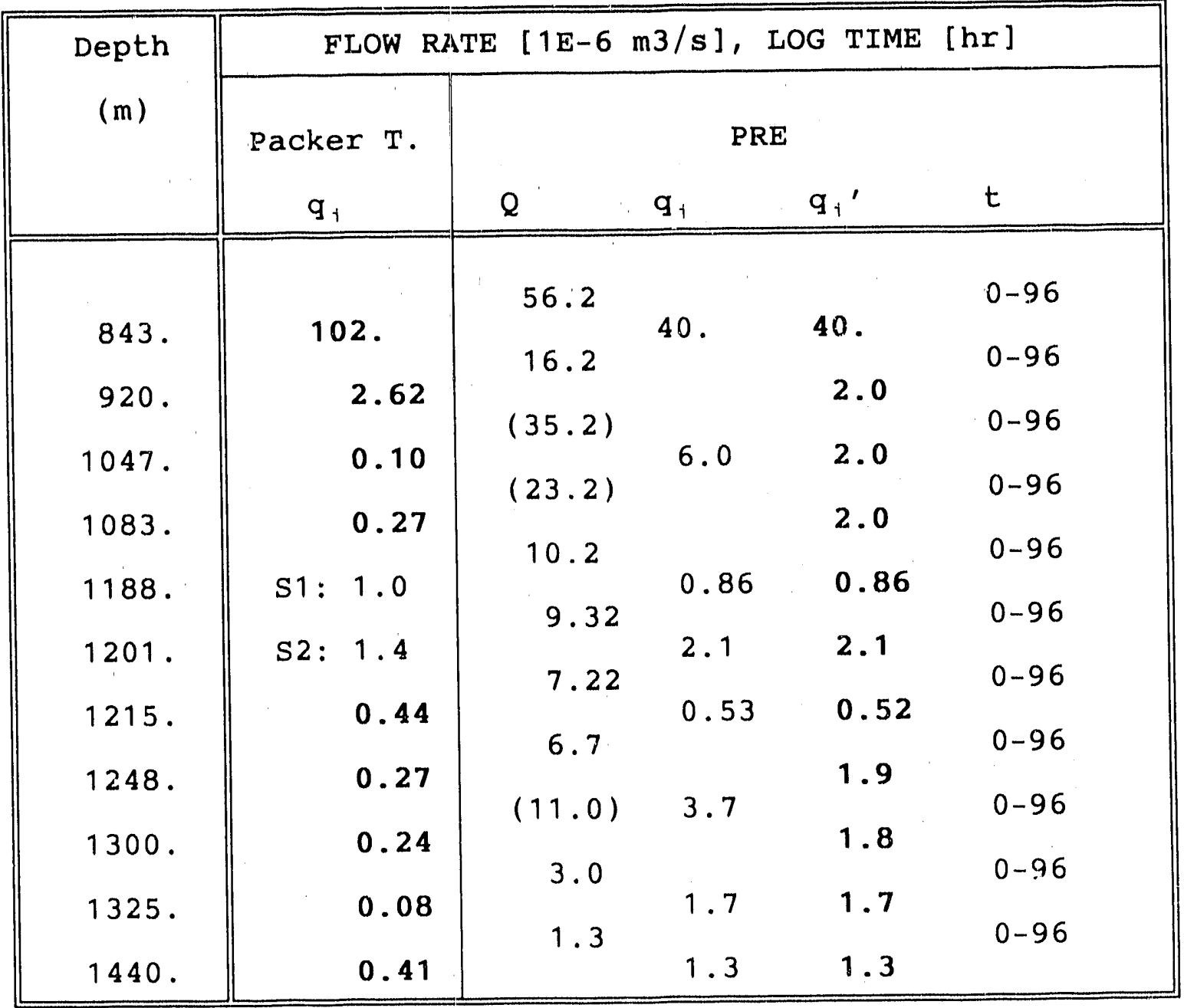

Table 6-3: Comparison of packer test derived $q^{\prime} s$ and PRE results for the Leuggern field data $\left(q_{i}=\right.$ primary fracture flow rate, $q_{i}{ }^{\prime}=$ adjusted fracture flow rate, $Q=$ wellbore flow rate in between fractures, $t=$ logging time of logs used for the a..alysis). The flux marked as "S2" corresponds to the summed fracture outflows for the fractures located at 1188,1202 and $1215 \mathrm{~m}$. The value marked with "S1" covers both outflows at 1188 and $1201 \mathrm{~m}$. 
We expect $Q$ to be monotonically increasing from the deep to the shallow parts of the well. However, we note that the value of $Q$ is abnormally large at depths of $1,300 \mathrm{~m}, 1,080 \mathrm{~m}$ and $1,047 \mathrm{~m}$. We make the assumption that these three results are the consequences of data inaccuracies and should be ignored. Thus $Q(920 \mathrm{~m})-Q(1,188 \mathrm{~m})$ represents total inflow from inflows at $1,188 \mathrm{~m}, 1,080 \mathrm{~m}$ and $1,047 \mathrm{~m}$; and $Q(1,248 \mathrm{~m})-Q(1,325 \mathrm{~m})$ represents total inflow from $1,325 \mathrm{~m}$ and $1,300 \mathrm{~m}$. The resulting values may form a valuable input and starting base for simulation and refinement with BORE. 


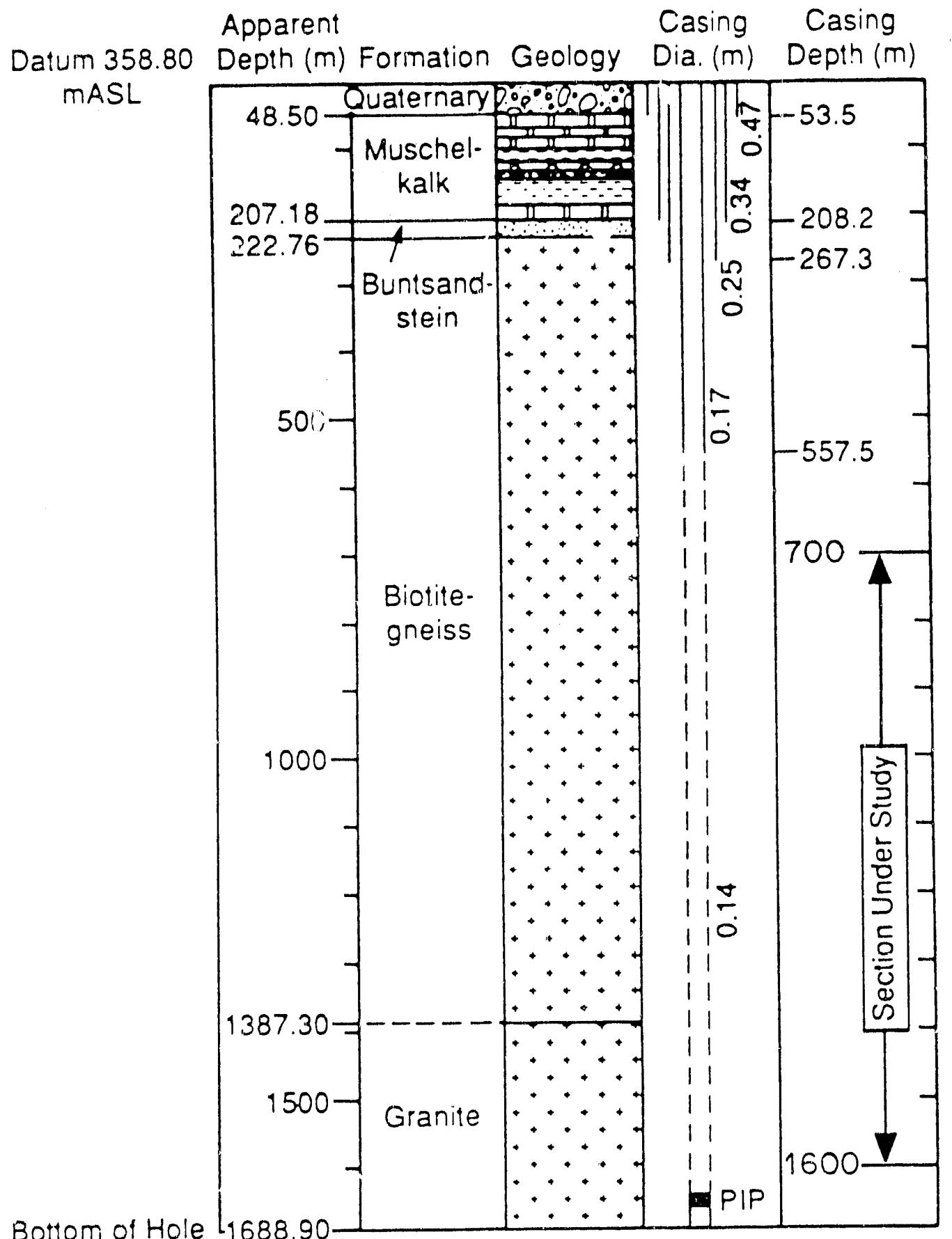

Fig. 6-1: Geology and borehole characteristics of the Leuggern borehole (mudified after TSANG et al. 1990) 


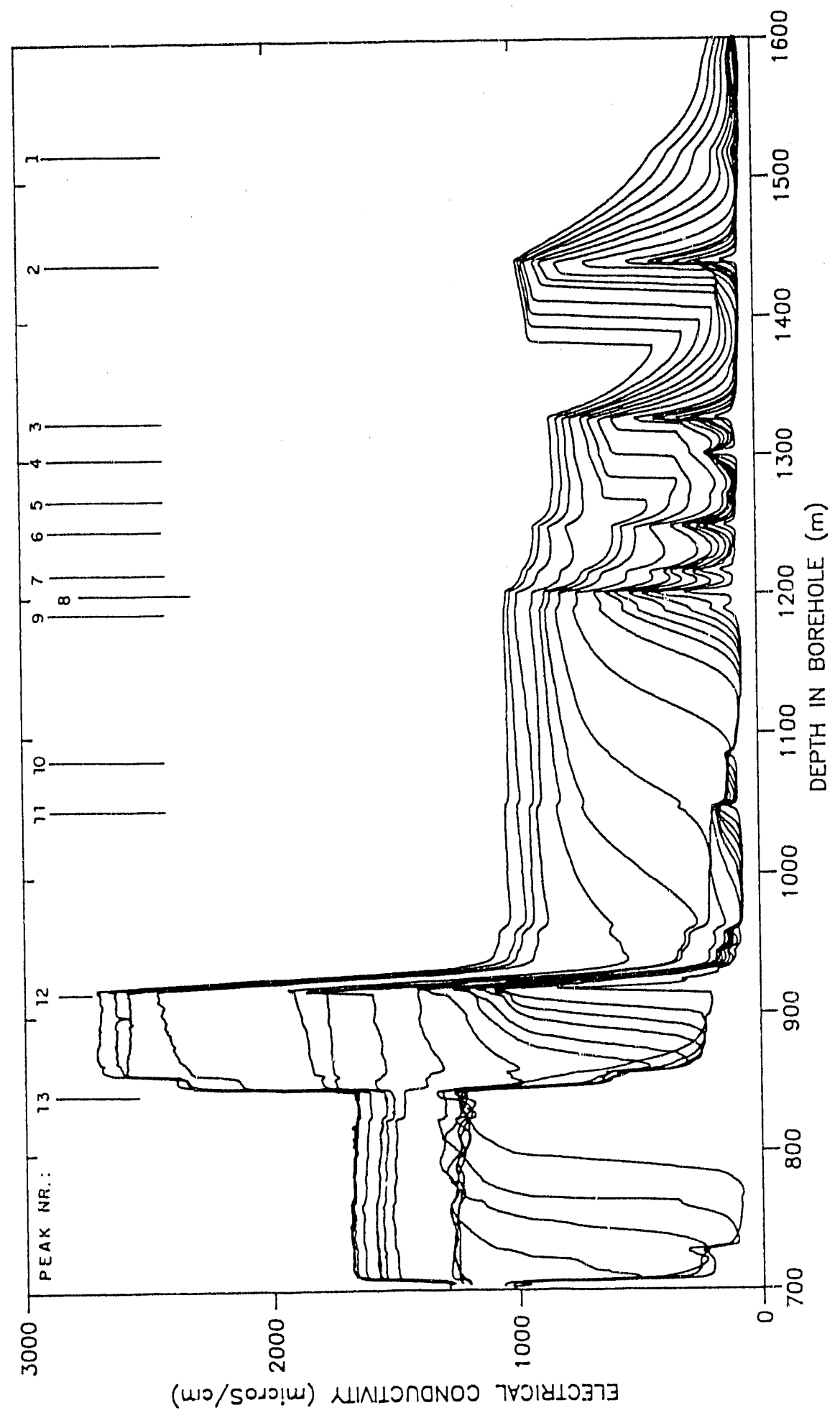

Fig. 6-2: Plot of the 1987 fluid logs measured in the Leuggern borehole 


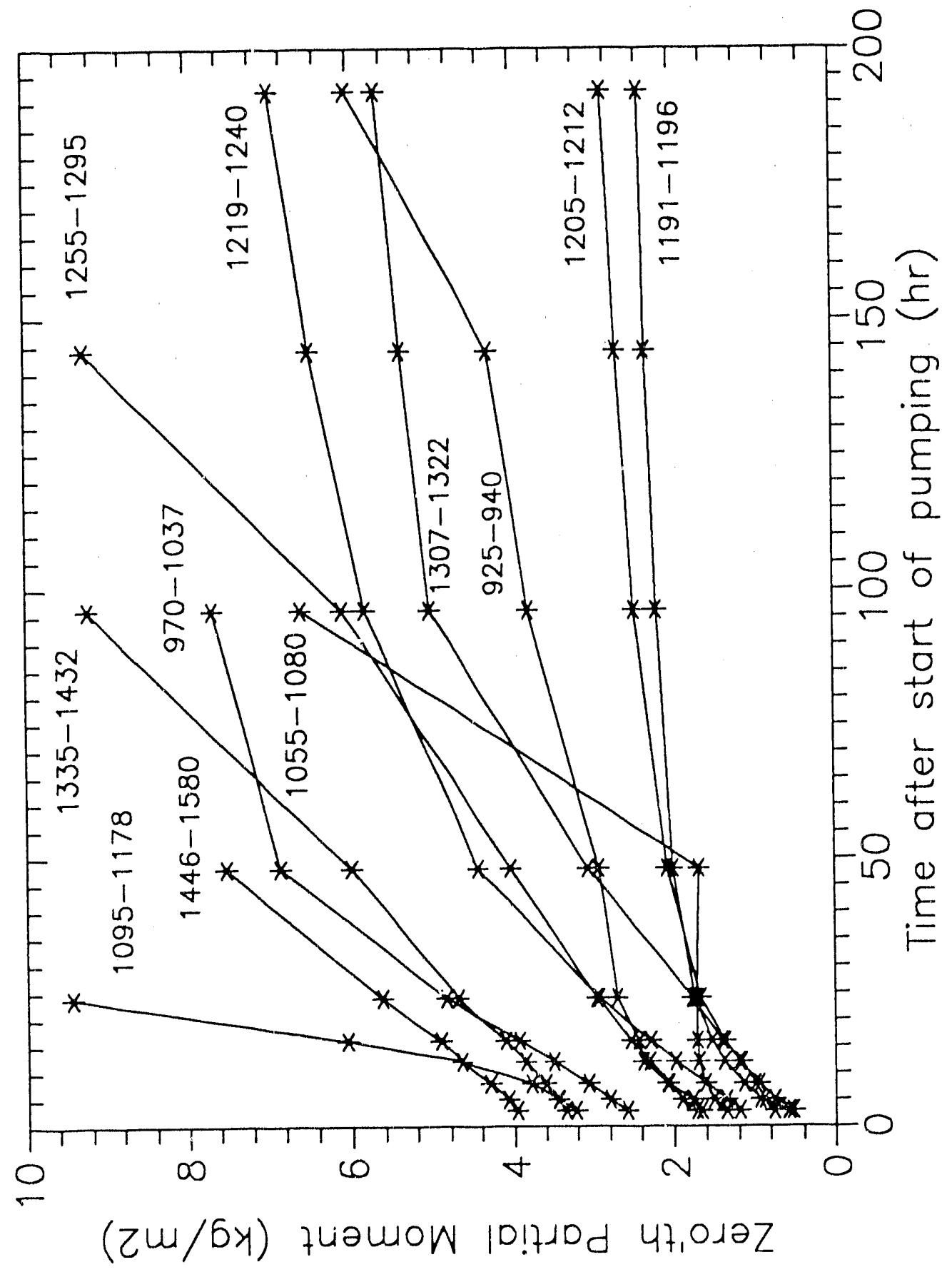

Fig. 6-3: Zero Partial Moment versus time for Leuggern 1987 field data 


\section{IMPLICATIONS FOR FIELD EXPERIMENT DESIGN AND DATA ANALYSIS}

\subsection{Field Experiment Design}

\section{WELLBORE FLUSHING PROCEDURE}

The analysis of fluid logging data can be performed with more direct approaches, and the results are in general more precise, when the fracture fluid concentrations $C_{;}$are constant with time. Therefore care should be taken when flushing the wellbore, in order to reduce the amount of flushing fluid injected into the formation to the absolute minimum. However, time variant fracture fluid concentrations (and fracture outflow rates) can be handled with the Partial Moment Method, as indicated in section 3.3 and verified with field data from the Siblingen borehole in KELLEY et a1. (1990).

\section{FLUSHING FLUID}

For numerical reasons the optimal choice of the concentration of the flushing fluid is constrained by the concentration of the formation fluid:

For numerically exact solutions of equation (2-4) (and (4-2)), ie. correct mass balances, the term $\beta$ describing the size of an outflow peak relative to the background:

$\beta=\left|\frac{t q_{i}\left(C_{i}-C_{0}\right)}{C_{0}\left(L_{0}-L\right) \pi r^{2}+t q_{i}\left(C_{i}-C_{0}\right)}\right|$

should not be so small as to cause severe rounding errors due to inaccuracies of the measured quantities. The term $\beta$ as defined ranges from zero, when the concentration $C_{i}$ of the outflow fluid from the fractures is close to the wellbore fluid concentration $C_{0}$, to 1 when $\left|t q_{i}\left(C_{i}-C_{0}\right)\right|$ is very large compared with $\left|C_{0}\left(L_{0}-L\right) \pi r^{2}\right|$. If precise determinations of the absolute masses released by a fracture $\left(\mathrm{tq}_{i} \mathrm{C}_{i}\right)$ are anticipated using zero moment quantities, then it is additionally required that $C_{i}$ and $C_{0}$ are similar in order of magnitude (see section 2.2 ). Thus one possible suggestion is that $\beta$ should be around 0.5 .

\section{LOGGING TIMES}

It should be noted, that for the case of time varying fracture parameters, the parameters $v$ and $k$ should be close to constant within an observation period (about 3 consecutive logging runs). This implies that the design should include a series of pairs or triples of logging runs distributed over the total logging time.

As demonstrated in sections 5 and 6 , it is in general sufficient to test during a relatively short total logging time (50-100 hrs), because 
he logs measured during this period contain the most important information with respect to fracture outflow rates (and transmissivities). Very late time data also provide important information with respect to fracture fluid electrolyte concentrations (comp. TSANG et al. 1990). However, in the light of test results and testing costs, such long test durations do not seem to be appropriate.

\subsection{Data Analysis Procedure}

An appropriate approach for the analysis of fluid electrical conductivity logs measured under the presence of fresh water or brine is presented on Fig. 7-1. The approach has been developed based on experience from field data analysis and consists of three major steps, name1y:

1. Check for Validity of Model Assumptions

2. First Estimate of Fracture Outflow Rates

3. Detailed Fracture Parameter Determination.

\section{STEP 1: CHECK FOR VALIDITY OF MODEL ASSUMPTIONS}

Previous analyses have shown that, even under very careful flushing conditions, substantial amounts of flushing (or drilling) fluids may enter into the formation and mix with the formation fluid, resulting in strongly varying fracture fluid outflow concentrations during the logging time (KELLEY et al. 1990). Other observations made in the past (e.g. by HECKEL, pers.com. 1990) show that, under certain test conditions, the wellbore electrolyte transport is influenced by effects of the upper or lower test boundary (pump, bottom of well). Finally, LOEW et al. (1989) show that minor density contrasts between the wellbore fluid and the fracture fluid (in the order of several per mill in case of brine) can lead to significant density driven flows when the wellbore velocity is very small. All these observations indicate that a careful examination of the appropriate conceptual model is required as the first analysis step, additionally to the fundamental assumptions of our governing equation discussed in section 1.2 .

An indication of the volumetric fracture fluid outflow rate as a function of time is given by the actual pumping rate and the relative production rates of the individual fractures affected by pumping. For a constant pumping rate the individual fractures can normally be assumed to show constant flow rates. Only in case of major (order of magnitudes) transmissivity or head differences between the fractures intersected might the minor productive fractures show early time transient flow.

An indication of the average fracture fluid value results from the ratio of the total mass released by all fractures intersected [integrating over the total logging section and accounting for mass flowing through the boundaries, see equations (2-4) and (4-2)] to the total volumetric flow (the pumping rate). This value can be calculated as a function of time and can be taken as an indication of the temporal concentration change of the fluids from the intersected fractures. 
Density driven flow is indicated by higher mass flow rates in the upstream (down the well) direction than in the downstream direction. The quantities defined by equation $(2-10)$ can be used for analysis. Effects of the upper or lower borehole boundary can be seen directly on the logs.

\section{STEP 2: FIRST ESTIMATE FRACTURE OUTFLOW RATES}

The methods described in sections 2 and 4 can be used to derive first estimates of the individual fracture fluxes and fracture fluid concentrations. While the classical moment approach can give good results for weakiy interfering peaks the Direct Integral Method is capable of estimating the relevant parameters also for interfering peaks.

\section{STEP 3: DETAILED FRACTURE PARAMETER DETERMINATION}

Depending on the results from step 1 , the detailed allalysis can either be performed by a Partial Mornent Analysis using the code MOMENT (LOEW and CALMBACH 1990), or by performing a best-fit analysis using a simulator like BORE (HALE and TSANG 1988) taking the results from step 2 as initial parameters. The conceptual model built into BORE assumes that the fracture parameters are time invariant and that transport through the 10 model boundaries is purely advective. The Partial Moment Method can treat time variant fracture parameters and is independent of model boundary effects. If only late time data are available or the data show a big scatter (large local deviations from the theoretical advectivediffusive transport profile) the Partial Moment Method might give unstable results. This second situation again is better analyzable with BORE, because local irregularities in the fluid logs have less effect when trying to fit entire peaks.

The results from the relatively quicix Partial Moment Analysis can also be used as input for BORE in a final simulation of the test and a direct comparison with the measured logs. In case of time invariant fracture parameters the simulation with BORE is straightforward. For time dependent fracture outflows, a series of BORE simulations with continuously updated background (starting) concentrations is required.

\subsection{Conclusions}

The new analysis methods described in the present report provide powerful supplements to the fluid logging methods derived in the past. The new analytical relationships and tools derived offer direct and relatively quick analysis procedures compared to manual best-fit simulations. Furthermore, the moment methods described are potentially capable of handling transient flow conditions and time variant fracture fluid concentrations, situations that were not amenable to analys is in the past. For the field case discussed in the present report, the Partial Moment Method results, even without use of BORE simulations, are ini very close agrecment with independently derived packer test results. 
The limitations of the different approaches presented vary from method to method. While the Classical Moment method fails when fracture outflow peaks are interfering, the Partial Moment Method can quickly exhibit numerical instabilities. These stem mostly from the fact that not only integral quantities are used in the analysis (as in the Direct Integral Method), but also local salinity gradients and integral time derivatives. The Direct Integral Method, while avoiding the derivatives with their potential instabilities, neglects diffusive electrolyte transport and is also dependent on the existence of non-interfering peaks at early times.

In conclusion, we believe and have demonstrated in this paper that these quick and direct methods, together with the BORE simulator, form an effective analysis package for borehole fluid electrical conductivity logs. Further applications and tests of their validity are foreseen. Additionally we plan on investigating the feasibility of fluid electrical conductivity measurements in mud-filled boreholes, where viscosity and density induced phenomena will have to be included in the analysis. 

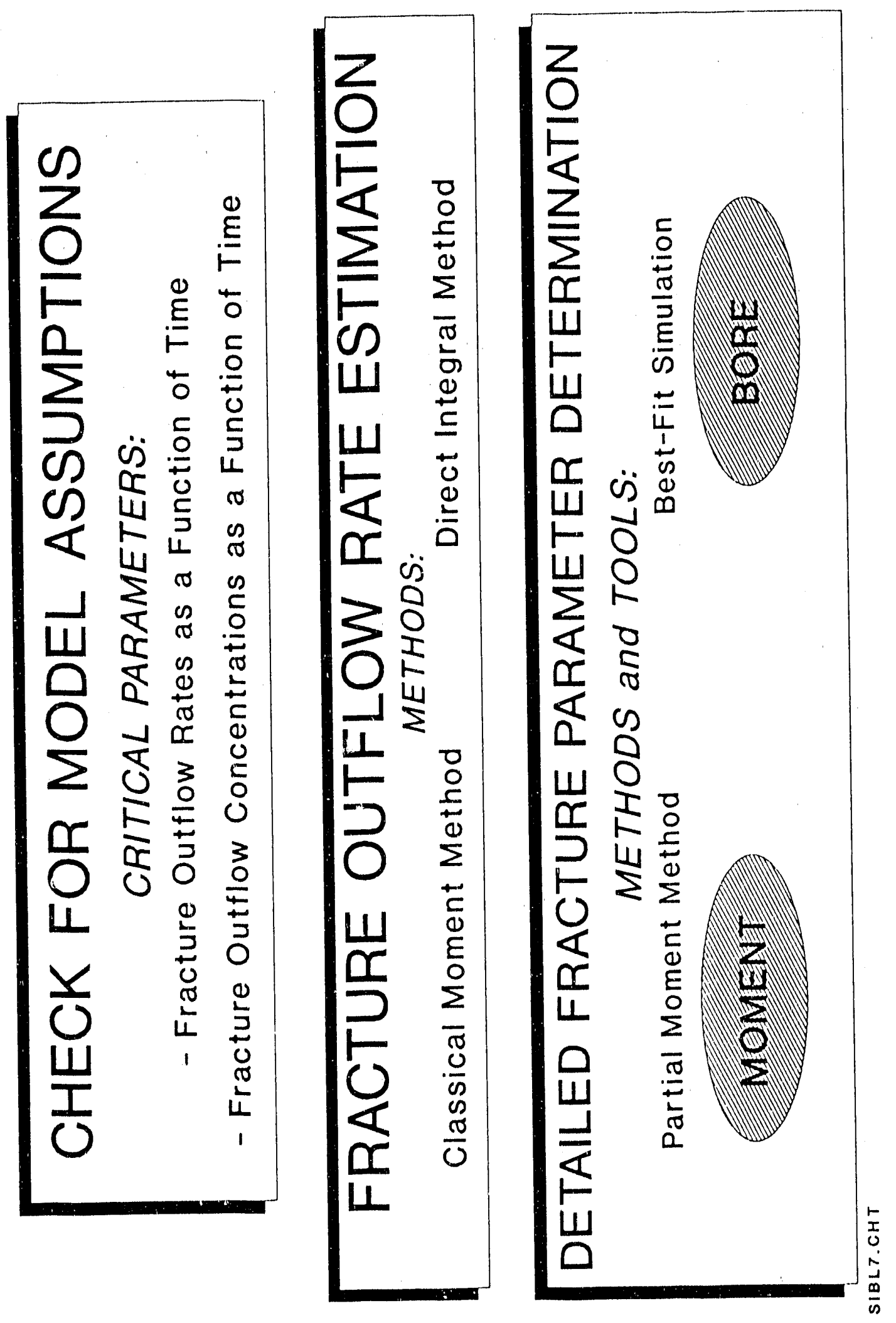

Fig. 7-1: Fluid logging analysis approach 


\section{REFERENCES}

ARIS, R. (1955): On the Dispersion of a Solute in a Fluid Flowing Through a Tube. - Proc. R. Soc., London, Series A-235, 67-77.

BEL.ANGER, D. W., FREEZE, G. A., Lolcama, J. L., \& Pickens J. F. (1989): Interpretation of Hydraulic Testing in Crystalline Rock at the Leuggern Borehole. - NAGRA Technischer Bericht 87-19, National Geriossenschaft für die Lagerung radioaktiver Abfälle, Baden, Switzerland.

COOPER, H. H., Jr. \& JACOB, C. E. (1946): A Generalized Graphical Method for Evaluating Formation Constants and Summarizing We11field History, AGU Transactions v. 27, No. 4, pp. 526-534.

FISCHER, H. B., LIST, E. J., KOH, R.C., IMBERGER, J. \& BROOKS, N.H. (1979): Mixing in Inland and Coastal Waters.- Academic Press Inc., New York.

HALE, F. V., \& TSANG, C. F. (1988): A Code to Compute Borehole Fluid Conductivity Profiles with Multiple Feed Points. - NAGRA Technischer Bericht 88-21, National Genossenschaft für die Lagerung radioaktiver Abfälle, Baden, Switzerland.

HALE, F.V. \& TSANG, C.F. (1989): A Direct Integral Method for the Analys is of Borehole Fluid Conductivity Logs to Determine Fracture Inflow Parameters. Unpublished Report Lawrence Berkeley Laboratory, CA, September 1988, modified as of November 1989.

JACOB, C. E. (1940): On the Flow of Water in an Elastic Artesian Aquifer. - AGU Transactions, v. 21, pp. 574 - 586.

KELLEY, V. A., LAVANCHY, J.-M., \& LOEW, S. (1990): Transmissivities and Heads Derived from Detailed Analys is of Siblingen 1989 Fluid Logging Data. - NAGRA Technischer Bericht in preparation, National Genossenschaft für die Lagerung radioaktiver Abfälle, Baden, Switzerland.

LOEW, S., MCNEISH, J. A., \& ANDREWS, R. W. (1989): Transmissivities Derived from Detailed Analysis of Leuggern 1987 Fluid Logging Data. - NAGRA Technischer Bericht in preparation, Nationale Genossenschaft für die Lagerung radioaktiver Abfälle, Baden, Switzerland.

LOEW, S. \& CALMBACH, L. (1990): MOMENT - A Code for the Analys is of Fluid Electrical Conductivity Logs in Boreholes Based on the Method of Moment Approach. - NAGRA Technischer Bericht in preparation, National Genossenschaft für die Lagerung radioaktiver Abfälle, Baden, Switzerland.

NAGRA (1989): Wellenberg, Arbeitsprogramm Teil 1. - NAGRA Technischer Bericht 89-12, National Genossenschaft für die Lagerung radioaktiver Abfälle, Baden, Switzerland. 
NAGRA (1990): Sondierbohrung Leuggern Untersuchungsbericht. - NAGRA Technischer Bericht in preparation, National Genossenschaft für die Lagerung radioaktiver Abfä!le, Baden, Switzerland.

ROBERTSON, J. A. \& CROWE, C. T (1985): Engineering Fluid Mechanics.Houghton Mifflin Publishing Company, Boston, Massachusetts.

SCHLUMBERGER Ltd (1984): Log Interpretation Charts. - New York.

TAYLOR, G. I. (1953): Dispersion of Soluble Matter in Solvent Flowing Slowly Through a Tube. - Proceedings of the Royal Society, Series A219, pp. 186 - 203.

TAYLOR, G. I. (1954): Conditions under which Dispersion of a Solute in a Stream of Solvent can be Used to Measure Molecular Diffusion. - Proc. R. Soc. London, Series A225, pp. 473 - 477.

THEIS, C. V. (1935): The Relationship between the Lowering of the Piezometric Surfuce and the Rate and Duration of Discharge of a Well Using Groundwater Storage. - AGU Transactions, v. 16, pp. 519-524.

TSANG, C. F. \& HUFSCHMIED, P. (1988): A Borehole Fluid Conductivity Logging Method for the Determination of Fracture Inflow Parameters. NAGRA Technical Report 88-13, NAGRA, Baden.

TSANG, C. F., HUFSCHMIED, P. \& F. V. Hale (1990): Determination of Fracture Inflow Parameters With a Borehole Fluid Conductivity Logging Method. Water Resources Research 26/4, pp. 561-578.

VERSTRAETE, P. (1988): Borehole Leuggern Report on Fluid Logging Program 1987. - NAGRA Interner Bericht, Nationale Genossenschaft für die Lagerung radioaktiver Abfälle, Baden, Switzerland. 

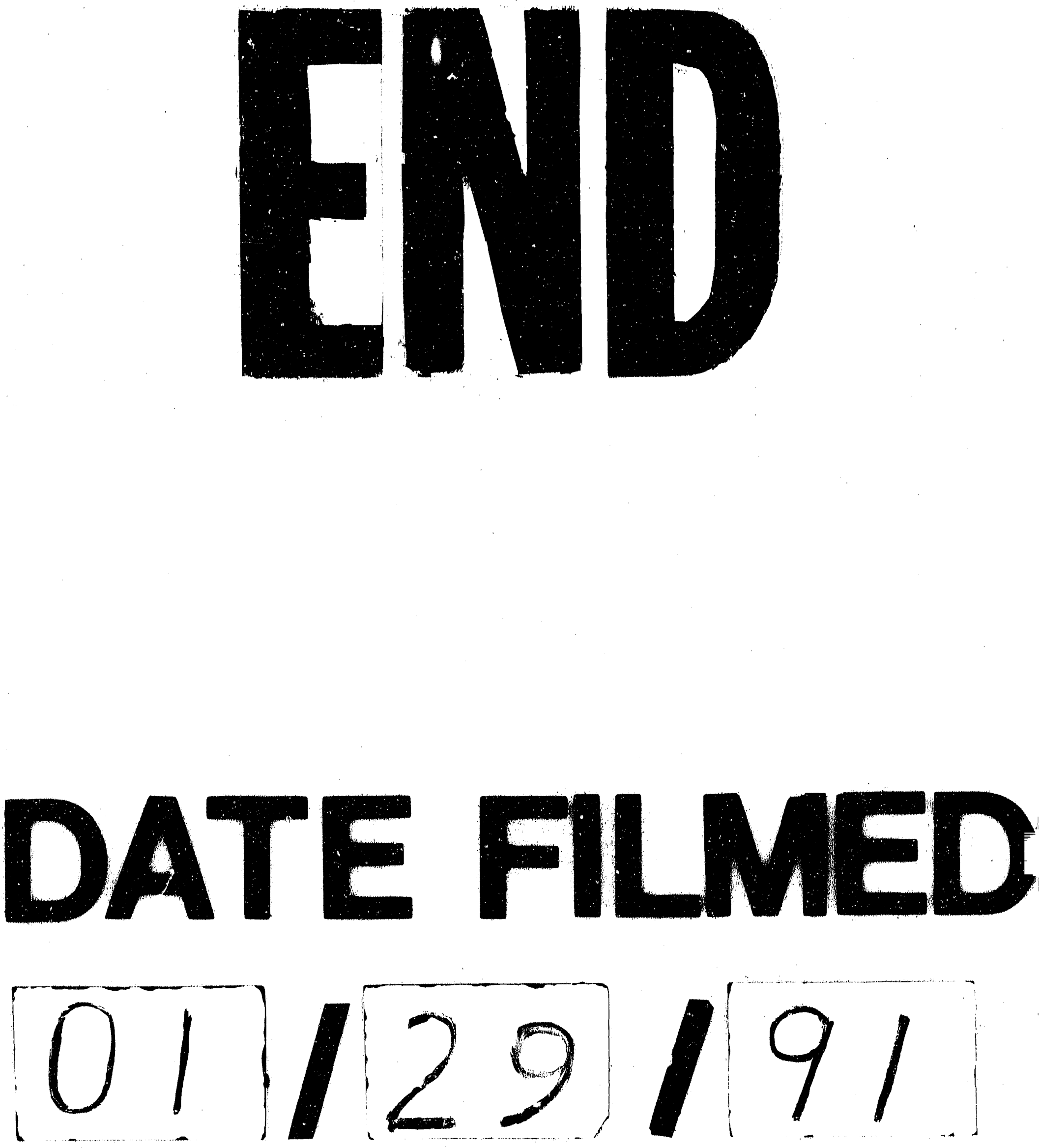
